\title{
Tendências recentes do crescimento populacional
}

\author{
HÉLIO A. DE MOURA e PERT TEIXEIRA
}

$\mathrm{N}$ ESTE TEXTO procura-se oferecer um balizamento a respeito do novo quadro evolutivo da população do Nordeste. Trata-se de algo que se afigugráfica que a regiăo vivanio em razão do monento histónico de transição democom a população regional implicavam ou diziam respeito e estavam associadas principalmente a questões ligadas à magnitude das suas taxas de crescimento. $\mathrm{O}$ próprio planejamento do desenvolvimento, tão em voga na região até meados dos anos 80, apoiava-se em projeções de população que no fundo, com maior ou menor sofisticação, correspondiam quase sempre a extrapolações de tendências históricas.

Entretanto, os últimos 10 a 15 anos corresponderam a período de rápidas mutações no comportamento das variáveis determinantes do crescimento demográfico regional. Entre elas, sem dúvida a rápida e persistente queda da fecundidade tornou-se a mais importante realidade emergente no panorama sócio-demográfico da região neste século. Atuando em conjugação com as demais variáveis demográficas (mortalidade e migração interna), tal queda deverá produzir efeitos que se farão sentir e repercutirão não só sobre a intensidade do crescimento, mas também sobre a distribuição espacial e sobre a própria estrutura da população do Nordeste, com todas as suas importantes conseqüências.

Dentro desse quadro de preocupações, apresenta-se inicialmente as tendências mais recentes do crescimento populacional da região de seus estados, destacando-se o crescimento da população urbana que, atualmente, já constitui o segmento majoritário do efetivo demográfico regional.

Em seguida, dedicar-se-á particular atenção à dinâmica demográfica regional, tratando especificamente de cada um de seus componentes: fecundidade, mortalidade e migração interna. No item seguinte analisar-se-ão as principais mudanças em curso na estrutura da população nordestina, procurando examinar as principais variações em curso ou que podem ser antevistas a curto e médio prazos, bem como as que lhes são conseqüentes em termos de demandas sociais.

No tópico final explicitam-se sumariamente algumas das principais questões e preocupações retidas desse esforço de análise, referem-se algumas prospecções sobre a evolução demográfica da região em anos vindouros e acrescentam-se algumas considerações a respeito. 


\section{Nordeste: $29 \%$ da população brasileira}

A região Nordeste, constituída pelos estados do Maranhão, Piauí, Ceará, Rio Grande do Norte, Paraíba, Pernambuco, Alagoas, Sergipe e Bahia tem a superfície de $1.566 \mathrm{mil} \mathrm{km}^{2}$, que corresponde a 18,3\% da área total do Brasil. Apresenta densidade demográfica da ordem de $27,5 \mathrm{hab} / \mathrm{km}^{2}$ que a situa em uma posição intermediária entre as densamente povoadas regiões Sudeste e Sul e as esparsamente povoadas regiões Norte e Centro-Oeste. Os resultados do Censo Demográfico de 1991 contabilizaram quase 42,5 milhões de pessoas residentes na região, representando cerca de $29 \%$ de toda a população brasileira. Mantida a tendência de crescimento registrada nos anos 80 , a sua população já deve andar, em 1997, à volta de quase 47 milhões de pessoas.

Tabela 1

Região Nordeste: população residente nas datas dos recenseamentos gerais e participação relativa sobre a população brasileira, por situação de domicílio

1940-1991

\begin{tabular}{ccccccc}
\hline \multirow{2}{*}{ Anos } & \multicolumn{5}{c}{ População (1000) } & \% s/ População brasileira \\
\cline { 2 - 7 } & Urbana & Rural & Total & Urbana & Rural & Total \\
\hline 1940 & $3.381,2$ & $11.052,9$ & $14.434,1$ & 26,3 & 39,0 & 35,0 \\
1950 & $4.744,8$ & $13.228,6$ & $17.973,4$ & 25,3 & 39,9 & 34,6 \\
1960 & $7.680,7$ & $14.748,2$ & $22.428,9$ & 24,0 & 37,9 & 31,6 \\
1970 & $11.980,9$ & $16.694,2$ & $28.675,1$ & 22,6 & 40,1 & 30,3 \\
1980 & $17.959,6$ & $17.459,5$ & $35.419,2$ & 21,9 & 44,6 & 29,2 \\
1991 & $25.753,4$ & $16.716,9$ & $42.470,2$ & 23,2 & 46,4 & 28,9 \\
\hline
\end{tabular}

Fonte: IBGE - Censos Demográficos

As tendências de crescimento da região Nordeste denotam histórica perda de posição relativa no conjunto da população brasileira (tabela 1). A referida perda está relacionada, principalmente, à que se observa com relação ao contingente titularmente urbano (1) da população cuja ligeira recuperação durante os anos 80 , não foi suficiente para reverter o comportamento tendencial da população ocorrida desde a década de 40 . Por sua vez, por efeito de uma desruralização mais tardia e/ou relativamente menos intensa da população nordestina (tabela 2), é possível verificar a crescente participação regional no âmbito da população rural brasileira. Em 1991, nada menos de $46 \%$ de todo o efetivo brasileiro já correspondiam à parcela residente no Nordeste. Assim sendo, as questões do campo deverão assumir, mais e mais, uma dimensão nordestina.

Prosseguiu também sem interrupção, ao longo da série, forte tendência à urbanização. Assim, em 1980, metade da população já residia em cidades e vilas, proporção que se elevou para quase $61 \%$ por ocasião do último Censo. Entre 1980 e 1991 cerca de $111 \%$ do crescimento populacional havido no Nordeste 
foram gerados e/ou absorvidos pelos quadro urbanos regionais (tabela 3). Significa dizer terem sido tais quadros capazes não só de absorver o equivalente a todo o próprio crescimento populacional líquido havido na região entre 1980 e 1991, mas também parcela do estoque básico de população residente nos seus quadros rurais no início desse período e que deixou o campo durante o seu transcurso.

Tabela 2

Região Nordeste e Brasil: taxa de crescimento populacional (\% a.a.) e grau de urbanização - 1940-1991

\begin{tabular}{|c|c|c|c|c|c|c|c|c|c|}
\hline \multirow[t]{2}{*}{ Período } & \multicolumn{3}{|c|}{ Região Nordeste } & \multicolumn{3}{|c|}{ Brasil } & \multirow[t]{2}{*}{ Anos } & \multicolumn{2}{|c|}{ Grau de urbanização } \\
\hline & Urbana & Rural & Total & Urbana & Rural & Total & & Nordeste & Brasil \\
\hline $1940-50$ & 3,5 & 1,8 & 2,2 & 3,1 & 1,6 & 2,3 & 1960 & 23,4 & 31,2 \\
\hline $1950-60$ & 4,9 & 1,1 & 2,2 & 5,5 & 1,6 & 3,2 & 1950 & 26,4 & 36,2 \\
\hline $1960-70$ & 4,6 & 1,3 & 2,5 & 5,2 & 0,7 & 2,9 & 1960 & 34,2 & 45,1 \\
\hline $1970-80$ & 4,1 & 0,5 & 2,1 & 4,5 & $-0,6$ & 2,5 & 1970 & 41,8 & 56,0 \\
\hline \multirow[t]{2}{*}{$1980-91$} & 3,3 & $-0,4$ & 1,7 & 2,8 & $-0,7$ & 1,8 & 1980 & 50,7 & 67,7 \\
\hline & & & & & & & 1991 & 60,6 & 75,5 \\
\hline
\end{tabular}

Fonte : IBGE - Censos Demográficos

A tabela 2 também evidencia que, até 1980, a taxa de crescimento da população nordestina mostrava-se inferior à da população brasileira. Sendo o Nordeste uma região a apresentar notoriamente índices de fecundidade bem superiores à média brasileira e, além disto, a caracterizar-se por uma situação de forte desvantagem relativa quanto ao seu desenvolvimento econômico e social, tais diferenças entre as taxas de crescimento das populações nordestina e brasileira refletem a grande importância desempenhada no passado pela migração interna. Funcionou esta como fator de ajustamento entre a abundância de sua oferta de mão-de-obra barata e a demanda pela mesma gerada em outras regiões do Brasil (Sudeste, principalmente), para atender às necessidades do desenvolvimento concentrado nos pólos dinâmicos da economia brasileira.

Contudo, o período 1980-1991 revela queda tanto na taxa de crescimento da população brasileira quanto na taxa de crescimento da população nordestina. Ambas decaíram para níveis que passaram a se mostrar bastante aproximados entre si: $1,8 \%$ a.a. no caso brasileiro; $1,7 \%$ a.a. no caso nordestino. Suspeita-se, no primeiro dos casos, que tal fato tenha resultado basicamente, embora não exclusivamente (2), da rápida queda da fecundidade iniciada nas regiões mais desenvolvidas e mais urbanizadas do país nos anos 70 e que, posteriormente, se estendeu ao resto do Brasil. Já no caso do Nordeste, é possível suspeitar que a queda da sua taxa de crescimento esteja a refletir de um lado, a extensão e/ou intensificação da queda da fecundidade como fenômeno emergente significativo no panorama demográfico regional dos anos 80 e, de outro lado, esteja também incorporando os efeitos sobre a migração interna relacionados com a longa 
recessão econômica por que passou a economia brasileira durante a maior parte do período considerado. Teria havido arrefecimento no saldo emigratório líquido de nordestinos para o resto do país, principalmente para a região Sudeste, como efeito tanto da prevalência, nessas áreas, de menores estímulos à atração de novos migrantes, quanto à permanência de migrantes antigos, que tenderiam a retornar à sua região de origem. Tais questões voltarão a ser tratadas em ocasião oportuna.

\section{O crescimento populacional dos estados}

Cerca de três quintas partes de todo o efetivo populacional da região Nordeste residiam, em 1991, em três dos seus nove estados: Bahia (27\%), Pernambuco (17\%) e Ceará (15\%). Os 40\% restantes distribuíam-se nas seis outras unidades da Federação, dentre as quais o Maranhão era a mais populosa (12\%) e Sergipe a que tinha menor participação relativa no cômputo regional (apenas 3,5\%). Os demais estados situavam-se em posição intermediária neste subconjunto, com participações relativas variando entre 6 e $8 \%$ (tabela 3 ).

Tabela 3

Região Nordeste: população residente (em 1000)

segundo a situação de domić́lio, por unidade da Federação - 1970-1991

\begin{tabular}{|c|c|c|c|c|c|c|c|c|c|}
\hline \multirow{3}{*}{$\begin{array}{l}\text { Unidades } \\
\text { da Federação }\end{array}$} & \multicolumn{3}{|c|}{ População urbana } & \multicolumn{3}{|c|}{ População rural } & \multicolumn{3}{|c|}{ População total } \\
\hline & 1970 & 1980 & 1991 & 1970 & 1980 & 1991 & 1970 & 1980 & 1991 \\
\hline & \multicolumn{9}{|c|}{ População residente } \\
\hline Maranhão & 771,8 & $1.296,4$ & $1.972,0$ & $2.265,3$ & $2.800,8$ & $2.957,0$ & $3.037,1$ & $4.097,2$ & $4.929,0$ \\
\hline Piauí & 561,1 & 931,2 & 1.3662 & $1.173,8$ & $1.256,9$ & $1.215,0$ & $1.734,9$ & $2.188,2$ & $2.581,2$ \\
\hline Ceará & $1.811,2$ & $2.877,6$ & $4.158,1$ & $2.680,4$ & $2.502,9$ & $2.204,6$ & $4.491,6$ & $5.380,4$ & $6.362,6$ \\
\hline R.G.Norte & 751,1 & $1.140,7$ & $1.668,2$ & 860,5 & 792,4 & 746,0 & $1.611,6$ & $1.933,1$ & $2.414,1$ \\
\hline Paraíba & $1.019,3$ & $1.479,7$ & $2.051,6$ & $1.426,1$ & $1.330,3$ & $1.149,1$ & $2.445,4$ & $2.810,0$ & $3.200,7$ \\
\hline Pernambuco & $2.862,5$ & $3.864,3$ & $5.046,5$ & $2.391,4$ & $2.380,0$ & $2.76,0$ & $5.253,9$ & $6.244,3$ & $7.122,5$ \\
\hline Alagoas & 642,2 & 995,3 & $1.481,1$ & 364,0 & $1.016,5$ & $1.031,9$ & $1.606,2$ & $2.011,9$ & $2.513,0$ \\
\hline Sergipe & 421,4 & 629,4 & $1.001,9$ & 489,9 & 527,2 & 489,2 & 911,3 & $1.156,6$ & $1.491,9$ \\
\hline Bahia & $3.140,4$ & $4.745,0$ & $7.007,7$ & $4.442,7$ & $4.852,4$ & $4.847,4$ & $7.583,1$ & $9.597,4$ & $11.855,2$ \\
\hline Nordeste & $11.980,9$ & $7.959,6$ & $25.753,4$ & $\begin{array}{r}16.694,2 \\
\%\end{array}$ & $\begin{array}{c}17.459,5 \\
\text { sobre o N }\end{array}$ & $\begin{array}{l}16.716,9 \\
\text { Jordeste }\end{array}$ & $28.675,1$ & $35.419,2$ & $42.470,2$ \\
\hline Maranhão & 6,4 & 7,2 & 7,7 & 13,6 & 16,0 & 17,7 & 10,6 & 11,6 & 11,6 \\
\hline Piauí & 4,7 & 5,2 & 5,3 & 7,0 & 7,2 & 7,3 & 6,1 & 6,2 & 6,1 \\
\hline Ceará & 15,1 & 16,0 & 16,2 & 16,1 & 14,3 & 13,2 & 15,7 & 15,2 & 15,0 \\
\hline R.G.Norte & 6,3 & 6,4 & 6,5 & 5,2 & 4,5 & 4,5 & 5,6 & 5,5 & 5,7 \\
\hline Paraíba & 8,5 & 8,2 & 8,0 & 8,5 & 7,6 & 6,9 & 8,5 & 7,9 & 7,5 \\
\hline Pernambuco & 23,9 & 21,5 & 19,5 & 14,3 & 13,7 & 12,4 & 18,3 & 17,6 & 16,8 \\
\hline Alagoas & 5,4 & 5,5 & 5,8 & 5,8 & 5,8 & 6,2 & 5,6 & 5,7 & 5,9 \\
\hline Sergipe & 3,5 & 3,5 & 3,9 & 2,9 & 3,0 & 2,9 & 3,2 & 3,3 & 3,5 \\
\hline Bahia & 26,2 & 26,4 & 27,2 & 26,6 & 27,8 & 29,0 & 26,4 & 27,1 & 27,9 \\
\hline Nordeste & 100,0 & 100,0 & 100,0 & 100,0 & 100,0 & 100,0 & 100,0 & 100,0 & 100,0 \\
\hline
\end{tabular}

Fonte: IBGE - Censos Demográficos 
Ao longo do tempo, tais proporções não apresentaram grandes variações, embora seja possível notar, nesse particular, alguma perda de posição relativa com respeito ao Ceará, à Paraíba e, principalmente, a Pernambuco. No tocante ao contingente titularmente urbano, os vários estados guardaram posições relativas assemelhadas àquelas pertinentes à população total, enquanto que, no tocante ao contingente rural, é digna de nota a crescente e já significativa participação relativa atingida pelo estado do Maranhão (cerca de 18\%).

A tabela 4 apresenta as taxas de crescimento da população regional segundo os estados e a situação do domicílio. Percebe-se que, em todos eles, com exceção do Rio Grande do Norte, foram verificados arrefecimentos no ritmo de crescimento das respectivas populações totais. Dentre os vários estados nordestinos, Pernambuco e Paraíba, seguidos por Piauí e Ceará foram aqueles cujas populações cresceram de forma mais lenta durante os anos 80: fizeram-no a taxas inferiores à média regional ( $1,7 \%$ a.a). A população de Sergipe, em primeiro lugar, mas também as de Alagoas e do Rio Grande do Norte destacaram-se por comportamento exatamente oposto. A mesma tabela demonstra também desintensificação significativa, entre os anos 70 e os anos 80 , no ritmo de crescimento da população residente nos quadros urbanos de quase todos os estados (com exceção de Sergipe). Pernambuco, neste particular, despontou como o estado nordestino cuja população urbana está a crescer de forma mais lenta $(2,5 \%$ a.a). No que tange à população rural, quase todos os estados apresentaram taxas negativas de crescimento, excetuando-se Maranhão e Alagoas.

Tabela 4

Região Nordeste e Brasil: taxas de crescimento da população residente segundo a situação do domicílio e grau de urbanização, por unidade de Federação 1970-1991

\begin{tabular}{|c|c|c|c|c|c|c|c|c|c|}
\hline \multirow[t]{2}{*}{ Estados } & \multicolumn{2}{|c|}{ Urbana } & \multicolumn{2}{|c|}{ Rural } & \multicolumn{2}{|l|}{ Total } & \multicolumn{3}{|c|}{ Grau de urbanização } \\
\hline & -80 & 980-91 & $1970-80$ & $1980-$ & L 1970-80 & 198 & -9119 & 01980 & 1991 \\
\hline Maranhão & 5,3 & 3,9 & 2,1 & 0,5 & 3,0 & 1,7 & 25,4 & 31,6 & 40,0 \\
\hline Piauí & 5,2 & 3,6 & 0,7 & $-0,3$ & 2,4 & 1,5 & 32,3 & 42,6 & 52,9 \\
\hline Ceará & 4,7 & 3,4 & $-0,7$ & $-1,1$ & 1,8 & 1,5 & 40,3 & 53,5 & 65,4 \\
\hline Rio G. Norte & 4,5 & 3,5 & $-0,8$ & $-0,6$ & 1,8 & 2,0 & 46,6 & 59,0 & 69,1 \\
\hline Paraíba & 3,8 & 3,0 & $-0,7$ & $-1,3$ & 1,4 & 1,2 & 41,7 & 52,7 & 64,1 \\
\hline Pernambuco & 3,1 & 2,5 & 0,0 & $-1,2$ & 1,7 & 1,2 & 54,5 & 61,9 & 70,9 \\
\hline Alagoas & 4,5 & 3,7 & 0,5 & 0,1 & 2,3 & 2,0 & 40,0 & 49,5 & 58,9 \\
\hline Sergipe & 4,1 & 4,3 & 0,7 & $-0,7$ & 2,4 & 2,3 & 46,2 & 54,4 & 67,2 \\
\hline Bahia & 4,2 & 3,6 & 0,9 & 0,0 & 2,4 & 1,9 & 41,4 & 49,4 & 59,1 \\
\hline Nordeste & 4,1 & 3,3 & 0,5 & $-0,4$ & 2,1 & 1,7 & 41,8 & 50,7 & 60,6 \\
\hline Brasil & 4,5 & 2,8 & $-0,6$ & $-0,8$ & 2,5 & 1,8 & 56,0 & 67,7 & 75,5 \\
\hline
\end{tabular}

Fonte: IBGE - Censos Demográficos

A tabela 4 também apresenta o grau de urbanização pertinente a cada estado (3). Não obstante a desintensificação havida no ritmo de crescimneto populacional urbano da região e de quase todos os seus estados, o grau de urba- 
nização de quase todos eles aumentou rapidamente ao longo do período observado, mercê dos amplos diferenciais verificados entre as taxas de crescimentos dos respectivos contingentes urbano e rural. Em 1991, todos os estados da região, menos o Maranhão, já apresentavam proporção majoritária de suas populações residindo em quadros urbanos. Os estados de Pernambuco, Rio Grande do Norte e Sergipe destacam-se como aqueles cujos contingentes urbanos afiguram-se relativamente mais expressivos.

$\mathrm{Na}$ tabela 5 , as relações contidas nas duas primeiras colunas refletem a importância relativa dos quadros urbanos no que concerne à absorção do crescimento populacional líquido registrado nos estados do Nordeste durante os subperíodos 1970-80 e 1980-91. Sem constituírem indicadores extremamente rigorosos, uma vez que mudanças na dinâmica do crescimento natural em cada um deles podem afetar as comparações intertemporais e entre estados, ainda assim tais relações permitem que se tenha uma idéia sobre a ordem de grandeza relativa da pressão populacional experimentada pelo meio urbano de cada estado.

Tabela 5

Região Nordeste: Absorção do crescimento populacional intercensitário segundo as unidades da Federação - 1970-80-91

\begin{tabular}{|c|c|c|c|c|c|c|}
\hline \multirow{3}{*}{$\begin{array}{l}\text { Unidades da } \\
\text { Federação } \\
\text { Maranhão }\end{array}$} & \multirow{2}{*}{\multicolumn{2}{|c|}{$\begin{array}{l}\text { \% Incremento da } \\
\text { população do estado } \\
\text { absorvidos pelos } \\
\text { quadros urbanos } \\
\text { 1970-80 1980-91 }\end{array}$}} & \multirow{2}{*}{\multicolumn{2}{|c|}{$\begin{array}{l}\text { \% Incremento da } \\
\text { população da região } \\
\text { Nordeste absorvido } \\
\text { pelos estados } \\
\text { 1970-80 1980-91 }\end{array}$}} & \multicolumn{2}{|c|}{$\begin{array}{l}\text { \% Incremento da } \\
\text { população do Brasi } \\
\text { absorvido pelos } \\
\text { estados do Nordeste }\end{array}$} \\
\hline & & & & & \multirow{2}{*}{$\begin{array}{c}1970-80 \\
4,0\end{array}$} & \multirow{2}{*}{$\begin{array}{c}1980-91 \\
3,2\end{array}$} \\
\hline & 49,5 & 81,2 & 15,7 & 11,8 & & \\
\hline Piauí & 81,7 & 110,7 & 6,7 & 5,6 & 1,7 & 1,5 \\
\hline Ceará & 120,0 & 130,4 & 13,2 & 13,9 & 3,3 & 3,8 \\
\hline Rio G. N. & 121.2 & 109,7 & 4,8 & 6,8 & 1,2 & 1,9 \\
\hline Paraíba & 126,3 & 146,6 & 5,4 & 5,5 & 1,4 & 1.5 \\
\hline Pernambuco & 101,2 & 134,6 & 14,7 & 12,6 & 3,7 & 3,4 \\
\hline Alagoas & 87,0 & 96,9 & 6,0 & 7,1 & 1,5 & 1,9 \\
\hline Sergipe & 84,8 & 111,1 & 3,6 & 4,7 & 0,9 & 1,3 \\
\hline Bahia & 79,7 & 100,2 & 29,9 & 32,0 & 7,6 & 8,8 \\
\hline Nordeste & 88,7 & 110,5 & 100,0 & 100,0 & 25,3 & 27,4 \\
\hline
\end{tabular}

Fonte: IBGE - Censos Demográficos

A comparação intertemporal dessas relações revela que, com a exceção menor do Rio Grande do Norte, tal pressão teria aumentado bastante em todos os estados durante a última década, sendo Paraíba, Pernambuco e Ceará os estados nos quais a mesma teria se manifestado de forma relativamente mais forte. Isso teria ocorrido inclusive por força da ampliação do processo de desruralização 
da população regional (4), identificado já nos anos 70 com relação aos estados do Ceará, da Paraíba, de Pernambuco e do Rio Grande do Norte, ampliado nos anos 80, de modo a incluir também o Piaú, Sergipe e a Bahia. No período 19801991 apenas os estados do Maranhão e de Alagoas apresentavam taxas de crescimento dos seus efetivos rurais que, apesar de diminutas, ainda se afiguravam positivas.

Assim, os anos 80, ao mesmo tempo em que foram marcados pela intensificação da pressão sobre o meio urbano regional, também corresponderam, no Nordeste ao limiar de um processo quase generalizado de desruralização populacional.

\section{As tendências do crescimento urbano}

Durante o período 1980-1991 a população residente no conjunto das cidades (sedes municipais) aumentou de 15,7 milhões de habitantes, no seu início, para 22,8 milhões, ao seu final. Embora o ritmo desse crescimento tenha sido relativamente rápido $(3,5 \%$ ao ano), ainda assim mostrou-se algo mais atenuado do que o da década precedente ( $3,9 \%$ ao ano). Além desse contingente o último Censo também registrou como população urbana cerca de 2,9 milhões de pessoas que residiam em vilas (sedes distritais) da região (tabela 6).

Tabela 6

Região Nordeste: número e população residente em cidades e vilas, segundo classes de tamanho - 1970-80-91

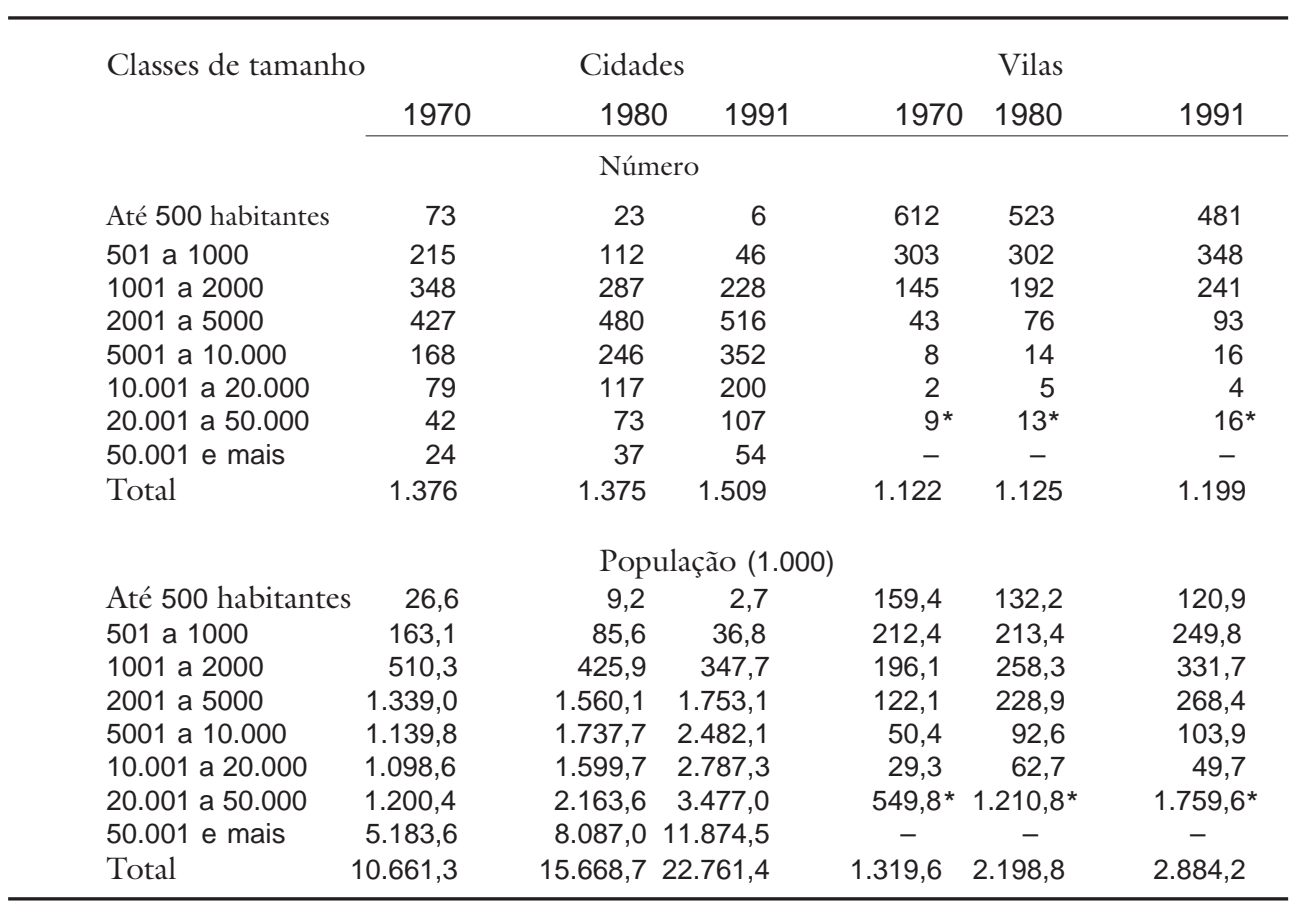

Nota: * Mais de 20 mil habitantes. Fonte: IBGE - Censos Demográficos 
Nos anos 80 aumentou bastante a participação relativa da população residente em cidades pequenas, classificadas em faixas de tamanho de 10 mil a 20 mil e de 20 mil a 50 mil habitantes: o crescimento dos efetivos populacionais assim distribuídos atingiu taxas anuais tão expressivas quanto, respectivamente, $5,2 \% \mathrm{e}$ $7,3 \%$ ao ano. Estas duas faixas, que do milhar e meio de cidades existentes na região classificam apenas 160 delas, foram responsáveis pelo crescimento e/ou absorção de aproximadamente $43 \%$ de todo o incremento populacional havido no conjunto das cidades nordestinas entre 1980 e 1991.

Percebe-se também a ocorrência, ao longo dos dois últimos períodos intercensitários, de forte redução no número e, por conseqüência, no volume do efetivo populacional residente em cidades de pequeníssimo porte (menos de dois mil habitantes). Não estaria havendo, nas últimas décadas, o surgimento de novas pequeníssimas cidades para preencher as lacunas deixadas pelo grande número daquelas que conseguiram ascender a patamares de maior tamanho.

Embora cadente, ainda assim mostrou-se expressiva (53\%) no período 1980 91 a participação das cidades classificadas na faixa de maior tamanho, isto é, com mais de 50 mil habitantes (tabela 7).

\section{Tabela 7}

Participação relativa no crescimento populacional urbano e taxas de crescimento demográfico segundo o tamanho das cidades - 1970-80-91

\begin{tabular}{|c|c|c|c|c|}
\hline \multirow[t]{2}{*}{ Classes de tamanho } & \multicolumn{2}{|c|}{$\begin{array}{c}\% \text { sobre o crescimento } \\
\text { total das cidades }\end{array}$} & \multicolumn{2}{|c|}{ Taxas de crescimento ( $\%$ a.a.) } \\
\hline & $1070-80$ & $1980-91$ & $1970-80$ & $1980-91$ \\
\hline Até 500 habitantes & $-0,3$ & $-0,1$ & $-10,1$ & $-10,6$ \\
\hline 501 a 1000 & $-1,6$ & $-0,7$ & $-6,2$ & $-7,4$ \\
\hline 1001 a 2000 & $-1,7$ & $-1,1$ & $-1,8$ & $-1,8$ \\
\hline 2001 a 5000 & 4,4 & 2,7 & 1,5 & 1,1 \\
\hline 5001 a 10.000 & 11,9 & 10,5 & 4,3 & 3,3 \\
\hline 10.001 a 20.000 & 10,0 & 16,7 & 3,8 & 5,2 \\
\hline 20.001 a 50.000 & 8,0 & 26,5 & 2,9 & 7,3 \\
\hline Mais de 50.000 & 58,0 & 53,4 & 4,6 & 3,6 \\
\hline Total & 100,0 & 100,0 & 100,0 & 100,0 \\
\hline
\end{tabular}

Fonte: IBGE - Censos Demográficos

A observação do componente urbano da população regional não pode deixar de lado, pela importância que assumem sob as mais diferentes facetas (econômica, social, artístico-cultural etc.), as três regiões metropolitanas do Nordeste: Recife, Salvador e Fortaleza. Ao longo do tempo, do ponto de vista da sócio-demografia regional, vinham sendo os focos de crescimento mais dinâmicos desse componente. Contudo, desde os anos 70 Recife já vinha apresentando sinais de arrefecimento do seu crescimento populacional, seja por efeito, ao que se presume, do início com que nela se antecipou a queda da fecundidade, seja por efeito da diluição do seu poder de atração migratória. Como demonstra a tabela 8, o fato é que a taxa de crescimento de sua população no período 1980- 
1991 já foi uma das mais baixas dentre todas as regiões metropolitanas brasileiras, bem aproximada à de São Paulo e somente superior à registrada para o Rio de Janeiro.

Tabela 8

Nordeste e Brasil: número de municípios e população residente nas regiões metropolitanas - 1980-1991

\begin{tabular}{|c|c|c|c|c|c|}
\hline \multirow[t]{3}{*}{$\begin{array}{l}\text { Regiões } \\
\text { metropolitanas }\end{array}$} & \multicolumn{2}{|c|}{$\begin{array}{c}\mathrm{N}^{\mathrm{o}} \text { de municípios } \\
\text { integrantes }\end{array}$} & \multicolumn{2}{|c|}{ População residente } & \multirow{2}{*}{$\begin{array}{c}\text { Taxa } \\
\text { de crescimento }\end{array}$} \\
\hline & 1980 & 1991 & 1980 & 1991 & \\
\hline & \multicolumn{4}{|c|}{ Nordeste } & \\
\hline - Recife & 5 & 8 & $2.348,4$ & $2.871,3$ & 1,8 \\
\hline - Salvador & 9 & 12 & $1.772,0$ & $2.493,2$ & 3,2 \\
\hline - Fortaleza & 8 & 10 & $1.581,6$ & $2.3032,6$ & 3,5 \\
\hline \multicolumn{6}{|l|}{ Outras regiões } \\
\hline - Belém & 2 & 2 & $1.000,3$ & $1.332,7$ & 2,6 \\
\hline - Belo Horizonte & 18 & 18 & $2.611,4$ & $3.431,8$ & 2,5 \\
\hline - Rio de Janeiro & 14 & 13 & $9.018,6$ & $9.796,5$ & 0,8 \\
\hline - São Paulo & 37 & 38 & $12.588,4$ & $15.416,4$ & 1,9 \\
\hline - Curitiba & 14 & 14 & $1.441,7$ & $1.998,8$ & 3,0 \\
\hline - Porto Alegre & 18 & 22 & $2.281,1$ & $3.026,0$ & 2,6 \\
\hline
\end{tabular}

Fonte: IBGE - Censos Demográficos

Não cabe tratar aqui com profundidade das determinações que estariam por trás desse desaquecimento, embora seja possível apontar em grandes linhas alguns fatores que parecem ter contribuído para a fragilização econômica dessa região metropolitana e, conseqüentemente, para a redução do seu outrora forte poder de atração migratória. Importa mencionar a decadência da agroindústria açucareira, historicamente a principal base de sustentação econômica do estado de Pernambuco e de sua capital, sem que se tivessem desenvolvido atividades econômicas de iguais porte e suporte. Paralelamente, há também que se ter em conta a deterioração da posição do Recife como grande empório ou entreposto comercial interessando a vasta área nordestina sob sua dominância. Isso se dava graças à posição geográfica estratégica do seu porto com relação às principais linhas do comércio marítimo por cabotagem ou de longo curso. À medida que o Nordeste foi se integrando por via rodoviária às demais regiões do país a partir dos anos 50, 60 e meados dos 70, o Recife foi também perdendo importância comercial, vendo seus estabelecimentos atacadistas pouco a pouco perderem a função distributiva que anteriormente exerciam relativamente a outras importantes praças nordestinas. As relações de compra e venda passaram, assim, a ser feitas diretamente entre essas praças e aquelas de outras regiões do país, principalmente do Sudeste. A nova tecnologia de compra e venda rapidamente adotada pelo comércio varejista regional, com a introdução do supermercado, parece ter 
jogado a pá de terra na importância comercial que a cidade do Recife e, por extensão, a sua região metropolitana antes desfrutara.

Um terceiro elemento explicativo do freio havido no crescimento demográfico da metrópole teria a ver com o fato de os efeitos migratórios representados pela desruralização populacional da Zona da Mata pernambucana, berço de atividade canavieira em franca decadência, terem sido em grande parte amortecidos pela existência, nessa zona, de uma malha urbana relativamente estruturada, constituída por cidades pequenas mas de relativa importância (de tamanho em torno de 20 mil a 100 mil habitantes). Estas, de certa forma, teriam absorvido parte de uma população cuja residência se desruralizou mas cuja atividade econômica permaneceu, mesmo em situação precária, sazonalmente vinculada ao campo e à cana. Incidentalmente, vale lembrar que isto talvez explique, em alguma medida, o intenso crescimento populacional observado com relação às cidades classificadas nas faixas de cidades de menor tamanho. Tais cidades teriam atuado e/ou estariam atuando como anteparos (5) à fuga maciça de camponeses para uma região metropolitana que, por seu turno, não estaria tendo condições de oferecer incentivos favoráveis a orientar a migração em sua direção. A hipótese de Todaro (1980) para explicar as relações entre a migração ruralurbana e a situação do emprego nos grandes centros urbanos dos países em desenvolvimento parece aqui ganhar grande força ao encontrar, no caso da região metropolitana do Recife, sugestiva e atualizada ilustração (6).

Quanto às duas outras regiões metropolitanas nordestinas - Salvador e Fortaleza - as tendências do seu crescimento populacional diferiram frontalmente das do Recife: as populações das duas metrópoles cresceram às taxas mais elevadas dentre todas as suas congêneres brasileiras no período 1980-91. O desenvolvimento econômico das duas regiões, baseado, no caso de Salvador, nas atividades do pólo petroquímico e no desenvolvimento de um pólo turístico de considerável importância e, no de Fortaleza, também no turismo e na montagem de um parque industrial de bens de consumo final com relativa intensidade na utilização do fator mão-de-obra, sem dúvida deve ter contribuído, via migração, para o elevado ritmo de crescimento das respectivas populações residentes. Acresce, no caso de Fortaleza, a inexistência de rede urbana bem estruturada em seu entorno, a determinar certa inexorabilidade quanto ao destino dos fluxos migratórios produzidos não só pelas secas mas, principalmente, pelas freqüentes estiagens parciais que afetam, de quando em vez, porções da vasta área semiárida sob influência da metrópole cearense. Considere-se, a propósito, que na migração rural-urbana nordestina, por fatores de natureza econômicoinstitucional, os deslocamentos causados pelas secas freqüentemente extrapolam a simples natureza episódica que o nosso folclore geralmente alardeia (7).

Entretanto, seja pelo gigantismo populacional a que já chegaram as duas metrópoles, seja pela queda da fecundidade que nelas estaria se fazendo presente, seja ainda por fatores outros ligados à migração mas que não se tem condição de precisar aqui, é bem provável que os anos 80 tenham correspondido ao início de uma fase de inflexão na tendência de aceleração do seu crescimento 
populacional. Assim, apenas estariam essas duas metrópoles defasadas em uma década em relação ao que já se registrou em todas as suas demais congêneres brasileiras (dados não apresentados). Tal suposição ganha corpo ao se comparar os dados do último Censo Demográfico com os resultados de uma projeção demográfica feita, em 1991, pelo Departamento de Estudos Populacionais (DESPO) da Fundação Joaquim Nabuco (8). Tal projeção, baseada nas tendências antevistas sobre a provável evolução das variáveis determinantes (fecundidade, mortalidade e migração interna) da dinâmica demográfica de cada microrregião a partir de uma análise cuidadosa e minuciosa sobre os respectivos comportamentos pretéritos, não se confirmou ao se comparar os resultados obtidos para essas duas cidades com os do Censo (9).

\section{A dinâmica demográfica}

O Nordeste caracterizava-se, até bem recentemente, pelas elevadas taxas de crescimento natural de sua população, marcadas por níveis de fecundidade muito altos e por níveis de mortalidade que, apesar de cadentes, ainda assim se mantinham elevados. Esse forte crescimento vegetativo que identificava a região era arrefecido por fluxos emigratórios líquidos que atuavam como fator de ajustamento em relação a um crescimento econômico que se mostrava incapaz de absorver, de forma produtiva, grande parte do efetivo populacional assim gerado.

Contudo, os dados censitários referentes aos anos 80 contradizem esse diagnóstico clássico. Nos itens seguintes serão apresentadas as novas tendências dessas variáveis como base para ajuizamento mais atualizado sobre a dinâmica demográfica em curso na região.

\section{A fecundidade}

Os primórdios da transição demográfica brasileira refletem os distintos níveis de desenvolvimento relativo entre as regiões e apontam para uma tendência que se desenvolveu de forma divergente entre os níveis da fecundidade pertinentes a cada uma delas. Assim, enquanto entre 1950 e 1970, as regiões Sul e Sudeste, as mais urbanizadas e desenvolvidas do país, apresentavam taxas de fecundidade total (10) inferiores à média brasileira, além de se mostrarem cadentes, o Nordeste (assim como as regiões Centro-Oeste e Norte), não só apresentava taxas muito elevadas mas estas também se afiguravam com aumentos ou com reduções muito débeis (tabela 9). Durante o período, as taxas de reprodução das mulheres nordestinas figuravam, de fato, entre as mais altas do país.

Como pode se observar, os anos 70 marcaram a generalização do processo de redução da fecundidade no Brasil, processo este que persiste até os dias atuais. No caso do Nordeste, cuja taxa de fecundidade esteve até 1970, entre 7 a 7,5 filhos por mulher, houve também persistente declínio, de forma a atingir, segundo o Censo Demográfico de 1991, 3,7 filhos por mulher, ou, segundo a PNDA de 1993, 3,3 filhos por mulher. 
Tabela 9

Brasil e Regiões: taxas de fecundidade total (TFT) - 1970-1993 (filhos/mulher)

\begin{tabular}{lllllll}
\hline \multirow{2}{*}{ Anos $\left(^{*}\right)$} & Nordeste & Sudeste & Sul & $\begin{array}{c}\text { Centro- } \\
\text { Oeste }\end{array}$ & Norte & Brasil \\
\cline { 2 - 6 } 1940 & 7,15 & 5,69 & 5,65 & 6,36 & 7,17 & 6,16 \\
1950 & 7,50 & 5,45 & 5,70 & 6,86 & 7,97 & 6,21 \\
1960 & 7,39 & 6,34 & 5,89 & 6,74 & 8,56 & 6,28 \\
1970 & 7,53 & 4,56 & 5,42 & 6,42 & 8,25 & 5,76 \\
1980 & 6,13 & 3,45 & 3,63 & 4,51 & 6,45 & 4,35 \\
1991 & 3,70 & 2,36 & 2,52 & 2,68 & 4,15 & 2,85 \\
1993 & 3,31 & 2,27 & 2,52 & 2,48 & $3,16 * *$ & 2,63 \\
\hline
\end{tabular}

Fontes:1940-1991: IBGE, Censos Demográficos...; Rodrigues, Roberto N. \& Wong, Laura R., Evolução da fecundidade na região Norte do Brasil, 1996 [inédito]; 1993: elaboração do DESPO/ FUNDAJ com base nos dados do IBGE (PNAD).

Notas: (*) Os anos estão referidos em relação aos dos levantamentos, embora, a rigor, as taxas devam ser melhor consideradas em termos de médias para intervalos qüinqüienais imediatamente anteriores aos Censos.

${ }^{* *}$ O valor refere-se exclusivamente aos quadros urbanos, uma vez que o PNAD não cobre as áreas rurais da região Norte.

A observação da tabela 10 indica, por sua vez, que a década de 80 marcou o começo de um processo de convergência entre as taxas de fecundidade atinentes às várias regiões brasileiras, a julgar pela maior intensidade relativa com que se reduziram a partir do início desse período as taxas de fecundidade pertinentes àquelas regiões que anteriormente as apresentavam situadas em patamares mais altos: casos do Nordeste e do Centro-Oeste, principalmente, mas também, em certa medida, da região Norte.

Tabela 10

Brasil e regiões: variação relativa das taxas de fecundidade total (TFT) - 1940-1991

\begin{tabular}{lcccrrr}
\hline & & & \multicolumn{5}{c}{$\begin{array}{c}\text { Centro- } \\
\text { Períodos }\end{array}$} & Nordeste & Sudeste & Sul & Oeste & Norte Brasil \\
\cline { 2 - 7 } & & & 0,9 & 7,9 & 11,2 & 0,8 \\
$1940-50$ & 4,9 & $-4,2$ & 3,3 & $-1,7$ & 7,4 & 1,1 \\
$1950-60$ & $-1,5$ & 6,3 & $-8,0$ & $-4,7$ & $-4,8$ & $-8,3$ \\
$1960-70$ & 1,9 & $-28,1$ & $-33,0$ & $-29,8$ & $-20,9$ & $-24,5$ \\
$1970-80$ & $-18,6$ & $-24,3$ & $-30,6$ & $-40,6$ & $-35,7$ & $-34,5$ \\
$1980-91$ & $-39,6$ & $-31,6$ & & & & \\
\hline
\end{tabular}

Fonte: IBGE (ver Tabela 9)

Obs.: Não se fez o cálculo com relação ao período entre 1991 e 1993 por repousarem as elaborações em fontes de dados distintos (Censo e PNAD, respectivamente).

Quando tais comparações descem em nível do quadro domiciliar, percebe-se que a mencionada convergência parece ficar restrita, pelo menos até o momento, à situação de residência urbana. Embora a taxa de fecundidade da população urbana nordestina tenha sido a que apresentou maior declínio relati- 
vo durante a década passada, exatamente o contrário ocorreu com relação à fecundidade do contingente rural; mesmo cadente ainda era, em 1991, de grandeza comparável à do Sudeste 11 anos antes, ou bem mais elevada do que a da região Sul nesse mesmo período. Assim, a extensão da queda da fecundidade a uma região específica como o Nordeste parece admitir forte diferenciação segundo a situação urbana ou rural de domicílio de sua população. Entre 1970 e 1991 cresceu o diferencial relativo entre as respectivas taxas de tal forma que em 1991, a taxa de fecundidade da população rural nordestina (5,3 filhos por mulher) já era superior em cerca de $80 \%$ à sua congênere urbana $(2,9$ filhos por mulher).

Tabela 11

Brasil e regiões: taxas de fecundidade total por situação do domicílio, 1970

\begin{tabular}{|c|c|c|c|c|c|c|}
\hline \multirow{3}{*}{$\begin{array}{l}\text { Anos ou } \\
\text { períodos }\end{array}$} & & \multicolumn{5}{|c|}{ Centro } \\
\hline & Nordeste & Sudeste & Sul & Oeste & Norte & Brasil \\
\hline & \multicolumn{6}{|c|}{ TFT (filhos/mulher) } \\
\hline \multicolumn{7}{|l|}{ Urbana } \\
\hline 1970 & 6,44 & 3,83 & 4,06 & 5,31 & 6,62 & 4,54 \\
\hline 1980 & 4,94 & 3,17 & 3,20 & 3,97 & 5,24 & 3,63 \\
\hline 1991 & 2,94 & 2,23 & 2,36 & 2,48 & 3,43 & 2,48 \\
\hline 1993 & 2,85 & - & - & - & - & - \\
\hline \multicolumn{7}{|l|}{ Rural } \\
\hline 1970 & 8,45 & 7,14 & 6,86 & 7,71 & 9,59 & 7,72 \\
\hline 1980 & 7,65 & 5,46 & 4,55 & 5,98 & 8,04 & 6,40 \\
\hline 1991 & 5,34 & 3,54 & 3,06 & 3,51 & 5,49 & 4,42 \\
\hline \multirow[t]{2}{*}{1993} & 4,49 & - & - & - & - & - \\
\hline & \multicolumn{6}{|c|}{ Variação relativa (\%) } \\
\hline \multicolumn{7}{|l|}{ Urbana } \\
\hline $1970 / 80$ & $-23,3$ & $-17,2$ & $-21,2$ & $-25,2$ & $-20,8$ & $-20,0$ \\
\hline $1980 / 91$ & $-40,5$ & $-29,7$ & $-26,3$ & $-37,5$ & $-34,5$ & $-31,7$ \\
\hline $1991 / 93$ & $-3,1$ & - & - & - & - & - \\
\hline \multicolumn{7}{|l|}{ Rural } \\
\hline $1970 / 80$ & $-9,5$ & $-23,5$ & $-33,7$ & $-22,4$ & $-16,2$ & $-17,1$ \\
\hline 1980/91 & $-30,2$ & $-35,2$ & $-32,7$ & $-41,3$ & $-31,7$ & $-30,9$ \\
\hline $1991 / 93$ & $-15,9$ & - & - & - & - & - \\
\hline
\end{tabular}

Fonte: Ver tabela 1

Os dados contidos na tabela 12, referentes aos anos recentes de 1991 e 1993, revelam também esse tipo de disparidade entre estados da região e entre os respectivos quadros de domicílio. Em que pesem as diferenças de fontes em que tais dados se baseiam, o que leva a não se comentar as variações ocorridas entre um ano e outro, servem eles para indicar, entre outros aspectos, ser o Maranhão o estado nordestino a apresentar o nível de fecundidade mais alto de todos. Tratase do estado menos urbanizado da região mas, não obstante, chama a atenção o fato de a sua fecundidade rural se mostrar inferior à urbana. Não se tem elementos disponíveis para explicar tal diferença, a menos que se trate de mera distorção estatística no cálculo dessas taxas; talvez seja possível aventar que a ocorrência tem a ver com o fato de o estado estar recebendo migrantes, em suas áreas rurais, 
provenientes de estados fronteiriços do Centro-Oeste, região que já apresenta fecundidade baixa e rapidamente cadente.

Contrariamente ao Maranhão, aos estados de Pernambuco, Rio Grande do Norte e Sergipe estariam correspondendo taxas de fecundidade menores por efeito da baixa fecundidade já prevalecente no seio de populações majoritariamente urbanas. Já o Ceará, o Piauí e, principalmente, Alagoas assumem destaque exatamente pelas altas taxas de fecundidade rural que ainda se lhes correspondem.

Os diferenciais para maior nos níveis da fecundidade rural situam-se, na maioria dos estados, entre $50 \%$ e $70 \%$ acima daqueles que dizem respeito aos respectivos quadros urbanos. Estados há, contudo, onde tal relação chega a ser superior a 2:1, seja por efeito da altíssima fecundidade que ainda ostentam os seus quadros, como é o caso de Alagoas, seja pelo baixo nível ao qual já desceu a fecundidade no meio urbano, como é o caso do Rio Grande do Norte.

Da observação dos dados contidos na tabela 12 , vale chamar a atenção a respeito de certa homogeneidade à qual já estaria chegando a fecundidade urbana dos vários estados da região, onde seis entre nove já estão apresentando taxas baixas a variar entre 2,7 e 2,1 filhos por mulher.

Como o desenvolvimento econômico brasileiro tem se dado, historicamente, de forma bastante diferenciada, seria lógico esperar que a magnitude dos respectivos diferenciais regionais e sociais viesse a se expressar, como realmente veio, em nível das variáveis determinantes do crescimento demográfico. Mas, o que estaria a determinar tal tendência, num plano sócio-econômico mais amplo, à convergência (11), já em níveis baixos, da fecundidade urbana entre as várias regiões brasileiras e entre os vários estados do Nordeste?

Autores há que atribuem a tendência à modernização por que vem passando a sociedade brasileira e à forte influência exercida pelos meios de comunicação social, principalmente a televisão, na divulgação de padrões modernos de comportamento reprodutivo prevalecentes em bairros sofisticados de classe média do Rio de Janeiro e de São Paulo. Contudo, a nosso ver, pelo menos no caso das áreas urbanas do Nordeste, haveria que também levar em conta o próprio caldo de cultura existente e propício à maximização dos efeitos dessa modernização à brasileira.

Este caldo seria representado pela existência, nas cidades nordestinas, de largos contingentes de população pauperizada, de pessoas desempregadas ou subempregadas, da prevalência de salários reais historicamente cadentes, enfim, de famílias ou indivíduos para os quais um filho representa um ônus de tal porte que explicaria a grande procura por esterilização feminina que se verifica na região (12) (com picos supostamente elevados durante os períodos eleitorais). 
Tabela 12

Nordeste: taxas de feminilidade total dos estados, por situação domiciliar - 1991 e 1993

\begin{tabular}{lllll}
\hline Estados & 1991 & & 1993 \\
\cline { 2 - 5 } & & Urbana & Rural & Total \\
Maranhão & 3,89 & 4,63 & 4,22 & 4,31 \\
Piauí & 3,11 & 2,95 & 4,54 & 3,52 \\
Ceará & 3,21 & 3,45 & 4,86 & 3,82 \\
Rio G. N. & 2,96 & 2,12 & 4,66 & 2,79 \\
Paraíba & 3,10 & 2,71 & 4,22 & 3,05 \\
Pernambuco & 2,82 & 2,37 & 3,92 & 2,68 \\
Alagoas & 3,27 & 2,76 & 6,11 & 3,83 \\
Sergipe & 3,16 & 2,25 & 3,52 & 2,51 \\
Bahia & 2,99 & 2,64 & 4,50 & 3,21 \\
\hline
\end{tabular}

Fontes dos dados básicos: IBGE, 1991: Censo Demográfico; 1993: PNAD.

( ) O cálculo das taxas foi elaborado pelo Departamento de Estudos Populacionais da Fundação Joaquim Nabuco.

A própria desruralização populacional em curso na região deve contribuir para acentuar a tendência. A saída maciça dos quadros rurais e a conseqüente residência nas cidades de um semiproletariado urbano pessimamente remunerado, em novo ambiente no qual as relações sociais são totalmente monetarizadas, deve ensejar, de um lado, queda significativa nos já baixos padrões de bem-estar e, de outro, a saída da mulher da esfera doméstica para exercer algum tipo de atividade econômica que lhe permita contribuir para o sustento da família. É óbvio que agora, na cidade, em tais condições, os filhos deixam de ser força de trabalho e passam a constituir estorvo: podem ser novas e caras bocas a alimentar!

Portanto, a fecundidade seria, hoje em dia, a principal variável sobre a qual as grandes massas de população pobre residente nas cidades da região teriam condições de atuar e exercer algum controle no afã de praticar o seu exercício quotidiano de sobrevivência.

\section{A mortalidade}

A esperança de vida ao nascer (13) constitui bom indicador da mortalidade em todas as idades por ter a vantagem de permitir comparar os seus níveis entre populações distintas não se deixando afetar por diferenças nas respectivas estruturas etárias.

As informações disponíveis a respeito acham-se sumariadas à tabela 13 . Como pode ser observado, é o Nordeste a região que historicamente tem apresentado os níveis de mortalidade mais altos do país. A vida média da população 
nordestina, em 1990, era de apenas 59 anos, longevidade que, apesar de superior em quase oito anos à sua média de uma década antes, ainda assim correspondia apenas à que a região Sul ostentava ao final dos já remotos anos 50.

Tabela 13

Brasil e regiões: esperança de vida ao nascer $\left(\mathrm{e}^{0}\right)-1970-1980$

\begin{tabular}{|c|c|c|c|c|c|c|}
\hline $\begin{array}{l}\text { Anos } \\
\text { ou período }\end{array}$ & s & Sudeste & $\begin{array}{l}\text { Regiões } \\
\text { Sul }\end{array}$ & Centro-Oeste & Norte & Brasil \\
\hline \multicolumn{7}{|c|}{$\mathrm{N}^{\mathrm{o}} \mathrm{s}$ absolutos (anos) } \\
\hline 1940 & 36,7 & 43,5 & 49,2 & 47,9 & 40,7 & 41,5 \\
\hline 1950 & 38,9 & 48,9 & 52,8 & 51,1 & 44,6 & 45,5 \\
\hline 1960 & 41,0 & 57,2 & 60,3 & 56,7 & 53,4 & 51,6 \\
\hline 1970 & 45,5 & 57,3 & 60,0 & 58,9 & 54,6 & 53,5 \\
\hline 1980 & 51,6 & 63,6 & 67,0 & 64,7 & 64,2 & 60,1 \\
\hline 1990 & 59,1 & 68,8 & 70,9 & 69,1 & 68,4 & 66,3 \\
\hline \multicolumn{7}{|c|}{ Variação relativa (\%) } \\
\hline $1940-50$ & 6,2 & 12,5 & 19,6 & 6,7 & 9,6 & 9,6 \\
\hline $1950-60$ & 5,2 & 16,8 & 2,6 & 10,8 & 19,7 & 13,5 \\
\hline $1960-70$ & 11,1 & 0,2 & $-0,5$ & 4,0 & 2,4 & 3,5 \\
\hline $1970-80$ & 13,2 & 11,0 & 11,6 & 9,8 & 17,5 & 12,4 \\
\hline $1980-90$ & 14,6 & 8,2 & 5,9 & 6,8 & 6,6 & 10,4 \\
\hline
\end{tabular}

Fonte: 1940-70: IBGE apud Pery Teixeira, Niveis de tendências da mortalidade, Recife, 1996 [ainda inédito]; 1980/90: ABEP/FNUAP, Diversidades brasileiras: um olhar demográfico, São Paulo, 1996.

É marcante o diferencial desfavorável ao Nordeste entre a longevidade de sua população e a da que reside no resto do país. De um lado, percebe-se convergência com relação aos crescentes níveis atingidos pelas populações residentes nas demais regiões brasileiras: em 1990, a vida média nessas regiões já variou no estreito intervalo de 68 anos, verificado na região Norte, e de 71 anos, na região Sul. A média nordestina ficou, assim, defasada entre 9 a 12 anos com relação à das demais regiões. É bem verdade que desde a década dos 60 , e com maior intensidade na dos 80 , vinha a população do Nordeste se beneficiando de declínios relativamente mais rápidos de sua mortalidade. Esse tipo de evolução pode ter a ver com certa incompressibilidade a que teria chegado o declínio da mortalidade nas regiões mais desenvolvidas do país: nelas já teriam sido eliminadas ou controladas em proporção maior muitas das causas exógenas de óbitos que podem ser eliminadas mais rapidamente e a baixo custo, inclusive via saneamento ambiental e medicina preventiva. Contudo, dado o baixo patamar em que a média nordestina se tem situado, os incrementos relativos mencionados não foram suficientes para fechar o elevado gap que ainda se verifica em relação as demais regiões. 
Descendo ao detalhe dos estados nordestinos (tabela 14), é possível verificar que os índices mais baixos de mortalidade corresponderam, tanto em 1980 quanto em 1991, às populações residentes no Nordeste setentrional (estados do Maranhão e Piauí) e no Nordeste meridional (estados de Sergipe e Bahia), atingindo níveis que se mostraram significativamente superiores à média regional. Mesmo assim, tais médias situaram-se, em 1990, entre 63 e 65 anos, mostrando-se bastante assemelhadas às que prevaleciam nas regiões Sudeste e Centro-Oeste no início da década passada. Já as populações dos estados do Nordeste central (Ceará, Rio Grande do Norte, Paraíba, Pernambuco e Alagoas) apresentaram vidas médias ainda muito baixas (entre 54 e 57 anos), não obstante terem sido aquelas cuja longevidade mais cresceu durante a década, tanto em termos absolutos, como relativos. Mesmo assim, a longevidade dos estados do Nordeste central ainda se mostrou muito baixa, em 1990, com vidas médias que variaram entre 54 e 57 anos.

Tabela 14

Nordeste: esperanças de vida ao nascer $\left(\mathrm{e}^{0}\right)$, segundo os estados - 1980 e 1990

\begin{tabular}{lcccc}
\hline \multirow{2}{*}{ Estados } & \multicolumn{2}{c}{$\mathrm{e}^{0} \mathrm{em}$ anos } & \multicolumn{2}{c}{$\begin{array}{c}\text { Variação } 1980 / 90 \\
\text { Absoluta }\end{array}$} \\
\cline { 2 - 5 } Maranhão & 1980 & 1991 & $\left(\mathrm{n}^{\circ}\right.$ de anos $)$ & Relativa $(\%)$ \\
Piauí & 55,4 & 62,7 & 7,3 & 13,2 \\
Ceará & 57,9 & 65,1 & 7,2 & 12,4 \\
Rio G. do Norte & 47,0 & 56,8 & 9,8 & 20,9 \\
Paraíba & 45,4 & 54,6 & 9,2 & 20,3 \\
Pernambuco & 44,4 & 53,7 & 9,3 & 21,0 \\
Alagoas & 47,8 & 56,6 & 8,8 & 18,4 \\
Sergipe & 46,9 & 55,7 & 8,8 & 18,8 \\
Bahia & 55,3 & 63,0 & 7,7 & 13,9 \\
Nordeste & 58,0 & 64,8 & 6,8 & 11,7 \\
& 51,6 & 59,1 & 7,5 & 14,5 \\
\hline
\end{tabular}

Fonte: APEB/FNUAP; Diversidades brasileiras: um olhar demográfico, São Paulo, 1996

Passa-se agora à observação das tendências da mortalidade na infância, ou seja, de um significativo segmento populacional sobre o qual, por óbvias razões, devem pairar e confluir grandes preocupações. Será adotado como indicador dessa variável a probabilidade da morte da criança até completar cinco anos de idade (14).

Historicamente, os níveis de mortalidade na infância têm declinado no Nordeste. A probabilidade de morte até os cinco anos de idade caiu, entre 1935 e 1990, de 309 para 95 óbitos por mil nascidos vivos. Tal redução não acompanhou, porém, o ritmo da que se verificou em nível de Brasil (de 241 para 59 por 
mil) e de demais regiões. Além disso, essa queda não foi constante ao longo do tempo, tendo sido de pouca intensidade até os anos 60 (16,8\% entre 1935 e 1965) e mais vigorosa a partir de então (69,3\% entre 1965 e 1990) (15).

Ao desagregar os resultados segundo os estados da região, percebe-se que tanto os níveis quanto as tendências da mortalidade na infância mostram-se bastante diferenciados. Até a década dos 60 , a mortalidade mais elevada concentrava-se nos estados do Nordeste central, enquanto que os níveis mais baixos diriam respeito à duas outras sub-regiões (Nordeste setentrional e Nordeste meridional). Três décadas depois, os estados classificados nesses três agrupamentos apresentaram valores em convergência, apesar dos importantes diferenciais ainda verificados. Note-se, por exemplo, as populações de Sergipe e do Rio Grande do Norte que eram, no início da série, as que apresentavam mais altas probabilidades de morte na infância, posicionavam-se ao final da mesma, como aquelas que apresentaram a situação mais satisfatória de todas (tabela 15).

Tabela 15

Nordeste: evolução da probabilidade de morte até cinco anos de idade - 1935-1990

\begin{tabular}{lllllll}
\hline & \multicolumn{3}{c}{ Probabilidade de morrer até cinco anos } \\
Estado & \multicolumn{9}{c}{ de idade } & & \multicolumn{2}{c}{ Redução (em \%) } \\
\cline { 2 - 7 } & 1935 & 1965 & 1990 & $1935-65$ & $1965-90$ & $1935-90$ \\
Maranhão & 0,256 & 0,186 & 0,102 & 27,3 & 45,1 & 60,1 \\
Piaú́ & 0,230 & 0,182 & 0,057 & 20,7 & 68,6 & 75,1 \\
Ceará & 0,268 & 0,242 & 0,093 & 9,6 & 61,4 & 65,1 \\
R.G. do N. & 0,357 & 0,301 & 0,067 & 15,5 & 77,7 & 81,1 \\
Paraíba & 0,341 & 0,269 & 0,106 & 21,2 & 53,5 & 68,9 \\
Pernambuco & 0,338 & 0,263 & 0,102 & 22,3 & 61,0 & 69,7 \\
Alagoas & 0,336 & 0,247 & 0,107 & 26,6 & 56,7 & 68,2 \\
Sergipe & 0,338 & 0,227 & 0,061 & 32,8 & 73,0 & 81,9 \\
Bahia & 0,267 & 0,192 & 0,075 & 28,0 & 51,9 & 71,9 \\
Nordeste & 0,309 & 0,232 & 0,095 & 24,9 & 59,1 & 69,3 \\
\hline
\end{tabular}

Fonte: IBGE - Censos Demográficos. Estimativas elaboradas pelo Departamento de Estudos Populacionais - INPSO-FUNDAJ

Como acontece em estruturas sociais complexas e marcadas por desigualdades, a mortalidade das crianças nordestinas também varia substancialmente entre subgrupos populacionais. Assim, cada nova desagregação de resultados oferece elementos complementares que permitem ressaltar novas facetas do fenômeno. É o que sucede, por exemplo, com a condição rural-urbana de residência da população. A tabela 16 mostra a evolução da mortalidade na infância segundo o quadro domiciliar declarado pelas mães por ocasião dos Censos 
Demográficos de 1970 e 1980 e da PNDA-1993. Nota-se que a mortalidade nas áreas urbanas foi quase sempre superior à das áreas rurais, em quase todos os estados, até meados dos anos 60 e que só a partir de então passaram as crianças residentes em áreas urbanas a ter sobrevivência maior ou igual (no caso do Maranhão) à das crianças residentes em áreas rurais (tabela 16).

Tabela 16

Nordeste: mortalidade na infância por situação de domićlio das mães segundo os estados - 1965-1985

\begin{tabular}{|c|c|c|c|c|c|c|c|c|c|c|}
\hline \multirow{3}{*}{ Estado } & & & & & & & \multicolumn{2}{|c|}{$\begin{array}{l}\text { Redução } \\
1965-75\end{array}$} & \multicolumn{2}{|c|}{$\begin{array}{l}\text { Redução } \\
\text { 1975-85 }\end{array}$} \\
\hline & \multicolumn{2}{|c|}{1965} & \multicolumn{2}{|c|}{1975} & \multicolumn{2}{|c|}{1985} & $\%$ & & $\%$ & \\
\hline & Urbano & Rural & Urbano & Rural & Urbano & o Rural & Urbano & o Rural & Urbanc & Io Rural \\
\hline Maranhão & 0,191 & 0,184 & 0,141 & 0,139 & 0,123 & 0,122 & 26,2 & 24,5 & 12,8 & 12,2 \\
\hline Piauí & 0,205 & 0,171 & 0,131 & 0,132 & 0,081 & 0,146 & 36,1 & 22,8 & 38,2 & $-10,6^{*}$ \\
\hline Ceará & 0,270 & 0,222 & 0,206 & 0,178 & 0,116 & 0,115 & 23,7 & 19,8 & 43,7 & 35,4 \\
\hline R.G.Norte & 0,294 & 0,307 & 0,215 & 0,221 & 0,085 & 0,145 & 26,9 & 28,0 & 60,5 & 34,4 \\
\hline Paraíba & 0,279 & 0,261 & 0,223 & 0,217 & 0,109 & 0,139 & 20,1 & 16,9 & 51,1 & 35,9 \\
\hline Pernambuco & 0,254 & 0,273 & 0,185 & 0,207 & 0,104 & 0,148 & 27,2 & 24,2 & 43,8 & 28,5 \\
\hline Alagoas & 0,241 & 0,250 & 0,198 & 0,208 & 0,106 & 0,181 & 17,8 & 16,8 & 46,5 & 13,0 \\
\hline Sergipe & 0,227 & 0,227 & 0,137 & 0,151 & 0,098 & 0,131 & 39,6 & 33,5 & 28,5 & 13,2 \\
\hline Bahia & 0,207 & 0,182 & 0,125 & 0,124 & 0,078 & 0,111 & 39,6 & 31,9 & 37,6 & 10,5 \\
\hline
\end{tabular}

Fonte: IBGE, Censos Demográficos. Estimativas elaboradas pelo Departamento de Estudos Populacionais INPSP-FUNDAJ.

Os dados disponíveis também indicam que a evolução vantajosa da sobrevivência infantil nas áreas urbanas da região, quando comparadas às áreas rurais, foi uma ocorrência que parece ter ficado mais restrita às capitais e aos seus municípios circunvizinhos. É o que sobressai na tabela 17 ao se observar a maior intensidade da queda da mortalidade nas regiões metropolitanas do Nordeste com relação às demais áreas urbanas dos estados onde se localizam.

Além disso, informações outras aqui não apresentadas (16) também indicaram que os níveis de mortalidade na infância entre os residentes em cidades interioranas e os residentes em áreas rurais não se diferenciavam muito entre si por ocasião da pesquisa PNDA-1993, apresentando, além disto, evoluções históricas muito assemelhadas.

Parece possível derivar daí a conclusão de que as ações de saúde infantil têm sido mais concentradas ou, pelo menos, mais eficazes no que concerne aos grandes centros urbanos (capitais e regiões metropolitanas), não se fazendo sentir seus efeitos em escala comparável, nem mesmo em nível das áreas urbanas dos municípios interioranos. 
Tabela 17

Ceará, Pernambuco e Salvador: mortalidade na infância segundo regiões metropolitanas e outras áreas urbanas - 1965-85

\begin{tabular}{lccccc}
\hline \multirow{2}{*}{$\begin{array}{l}\text { Regiões } \\
\text { metropolitanas e } \\
\text { outras áreas urbanas }\end{array}$} & 1965 & 1975 & 1985 & $1965-75$ & $1975-85$ \\
\cline { 2 - 5 } & & & & & \multicolumn{2}{c}{ Redução } \\
Fortaleza & 0,268 & 0,192 & 0,096 & 28,3 & 50,0 \\
Recife & 0,224 & 0,148 & 0,085 & 33,9 & 42,6 \\
Salvador & 0,203 & 0,103 & 0,057 & 49,3 & 44,7 \\
Ceará & 0,272 & 0,222 & 0,146 & 18,4 & 34,2 \\
Pernambuco & 0,298 & 0,233 & 0,152 & 21,8 & 34,8 \\
Bahia & 0,210 & 0,137 & 0,083 & 34,8 & 39,4 \\
\hline
\end{tabular}

Fonte: IBGE, Censos Demográficos - Estimativas elaboradas pelo Departamento de Estudos Populacionais - INPSO-FUNDAJ

\section{Migração interna}

A taxa de migração líquida (interregional) calculada para o Nordeste como um todo indica que, nos anos 80 , prosseguiu a tendência de arrefecimento identificada já na década anterior. Entre um e outro destes períodos, a referida taxa decresceu de 4,1 por mil para 2,5 por mil (tabela 18). Estima-se que a evasão líquida de nordestinos tenha atingido, entre 1980 e 1991, magnitude da ordem de 1,1 milhão de pessoas, ou seja, cerca de 300 mil migrantes a menos do que foi estimado com relação à década anterior. Assim, o fluxo emigratório dos anos 80 teria caído a quase metade do que se verificou na remota década de 60 (tabela 19).

Fatores vários estariam determinando tal queda ou a ela associados. De um lado, seria efeito combinado da desintensificação no fluxo emigratório (saída) de nordestinos e intensificação no daquelas pessoas que teriam ingressado no Nordeste, inclusive a parcela de nordestinos que estariam regressando à região (migrantes de retorno). Como se sabe, ao longo de sua história, o Nordeste tem tido na emigração a principal forma pela qual o crescimento vegetativo elevado de sua população se tem ajustado ao crescimento econômico que se tem mostrado incapaz de absorvê-lo integralmente de forma produtiva. Embora os dados disponíveis não permitam estimar com a precisão necessária a importância assumida pelas variáveis de natureza econômica para o arrefecimento observado na emigração líquida interregional, há, pelo menos, que aludir a menor força de atração que estariam tendo os mercados de trabalho do resto do país ao perderem sua capacidade de geração de empregos e, conseqüentemente, de absorção e retenção efetiva, da força de trabalho. É uma perda que deve ter sido percebida pelos migrantes em potencial. Há também que se atribuir a esse mesmo determinante a possível intensificação do fluxo migratório de retorno ao Nordeste. 
Além disso, os fluxos emigratórios regionais têm sido freqüentemente engrossados por retirantes das secas ou de estiagens que ciclicamente assolam vastas porções da zona semi-árida da região, mas que praticamente não ocorreram durante os anos 80, ou pelo menos, não com a freqüência de intensidade de décadas anteriores.

Tabela 18

Nordeste: taxas de migração líquida segundo os estados - 1960-1991 (por mil)

\begin{tabular}{lrrrrrrr}
\hline \multirow{3}{*}{ Estados } & \multicolumn{3}{c}{$1960-70$} & \multicolumn{3}{c}{$1970-80$} & $1980-91$ \\
& Urbana & Rural & Total & Urbana & Rural & Total & Total \\
\cline { 2 - 8 } Maranhão & 19,5 & $-25,2$ & $-16,1$ & $-25,7$ & $-12,2$ & $-1,8$ & $-7,5$ \\
Piauí & 28,4 & $-18,2$ & $-5,4$ & 25,6 & $-26,6$ & 7,3 & 5,5 \\
Ceará & 22,5 & $-17,1$ & $-2,3$ & 28,0 & $-35,5$ & $-3,6$ & $-1,9$ \\
R.G. de N. & 29,4 & $-17,9$ & 2,3 & 25,4 & $-28,3$ & 1,8 & 4,7 \\
Paraíba & 12,6 & $-26,6$ & $-11,3$ & 22,3 & $-27,8$ & $-4,0$ & $-2,2$ \\
Pernambuco & 17,6 & $-26,5$ & $-4,4$ & 12,4 & $-23,7$ & $-2,5$ & $-3,6$ \\
Alagoas & 13,7 & $-20,0$ & $-7,2$ & 24,1 & $-24,2$ & $-2,2$ & 1,4 \\
Sergipe & 9,5 & $-32,7$ & $-14,4$ & 18,1 & $-24,2$ & $-2,4$ & 4,8 \\
Bahia & 11,1 & $-24,7$ & $-9,0$ & 15,9 & $-22,6$ & $-4,6$ & $-0,6$ \\
Nordeste & 16,7 & $-23,1$ & $-7,3$ & 28,8 & $-24,1$ & $-4,1$ & $-2,5$ \\
\hline
\end{tabular}

Tabela 19

Nordeste e estados: volume da migração líquida durante os intervalos censitários - 1960-1991

\begin{tabular}{lccc}
\hline \multirow{2}{*}{ Estados } & \multicolumn{3}{c}{ Milhares de pessoas } \\
& $1960-70$ & $1970-80$ & $1980-91$ \\
\cline { 2 - 4 } Maranhão & $-509,2$ & 68,6 & - \\
Piauí & $-89,5$ & $-156,9$ & 414,9 \\
Ceará & $-98,1$ & 192,2 & $-132,9$ \\
R.G. do N. & 33,7 & 33,1 & 118,7 \\
Paraíba & $-277,4$ & $-111,2$ & $-76,9$ \\
Pernambuco & $-228,7$ & 54,7 & $-284,1$ \\
Alagoas & $-115,2$ & $-44,0$ & 38,1 \\
Sergipe & $-136,0$ & $-27,3$ & 75,4 \\
Bahia & $-683,4$ & $-430,9$ & $-76,7$ \\
Nordeste & $-2.058,04$ & $-1.416,2$ & $-1.143,5$ \\
\hline
\end{tabular}

Fontes: 1960-70-80: Moura, Hélio A. \& Santos, Taís F., Dinâmica demográfica recente dos estados e microrregi $\bullet$ es do Nordeste, FUNDAJ, 1986; 1980-91: Estimativas preliminares realizadas pelos autores. Nota: Os valores negativos correspondem a situações de emigração líquida.

Há também que ter em conta um fator até há pouco deixado à margem na análise da migração nordestina dada a constância em que se mantinham os níveis da fecundidade na região. Trata-se do declínio em curso na taxa de crescimento vegetativo da população por efeito da queda da fecundidade. Admite-se que isso 
tenha atuado no sentido de provocar redução do próprio potencial migratório da região. A fim de aquilatar a real importância que teve a queda da fecundidade no sentido de inibir a migração regional, procurou-se elaborar a estimativa que consta da tabela 20. A questão que está por trás dessa elaboração é a seguinte: qual teria sido a magnitude da emigração líquida nordestina, entre 1980 e 1991, se a população residente na região, em início desse período, tivesse crescido vegetativamente à mesma taxa com que o fez na década anterior? Não obstante a extrema cautela com que os resultados desse exercício devem ser considerados (17), eles servem para a importância que a queda da fecundidade assumiu no sentido de amortecer o volume da emigração líquida nordestina, ocorrida nos anos 80 . O potencial migratório estimado para a região foi da ordem de 3,3 milhões de pessoas o qual, ao ser comparado com a magnitude do fluxo representativo da migração ocorrida no mesmo período, indica que apenas uma de suas terças partes converteu-se em migração de fato. A queda da fecundidade teria pois ceifado duas terças partes do potencial estimado.

Tabela 20

Nordeste e estados: efeito da queda do crescimento vegetativo sobre o volume da migração interregional - 1980-91

\begin{tabular}{|c|c|c|c|c|c|c|}
\hline \multirow[t]{3}{*}{ Estados } & \multicolumn{4}{|c|}{$\begin{array}{l}\text { Crescimento vegetativo } \\
\text { (\% a.a.) }\end{array}$} & \multicolumn{2}{|c|}{$\begin{array}{c}\text { Efeito inibidor do } \\
\text { crescimento vegetativo } \\
\text { sobre a miração }\end{array}$} \\
\hline & $1970-80$ & L980-91 & Potencial* & Efetivada & Em mil & Em \% \\
\hline & $(\mathrm{I})$ & (II) & $(\mathrm{III})$ & $(\mathrm{IV})$ & $(\mathrm{V}=\mathrm{IV}-\mathrm{III})$ & $(\mathrm{VI}=\mathrm{V} / \mathrm{III})$ \\
\hline Maranhão & 31,1 & 24,4 & $-808,9$ & $-414,1$ & $-394,8$ & 48,8 \\
\hline Piauí & 31,7 & 20,6 & $-503,2$ & $-323,9$ & $-179,3$ & 35,6 \\
\hline Ceará & 23,1 & 17.3 & $-555,1$ & $-132,9$ & 422,2 & 76,1 \\
\hline R.G.N. & 18,7 & 15,7 & 45,0 & 118,7 & 73,7 & 163,8 \\
\hline Paraíba & 19,2 & 14,1 & $-263,2$ & $-76,9$ & $-186,3$ & 70,8 \\
\hline Pernambuco & 20,1 & 15,6 & $-650,7$ & $-284,1$ & 366,6 & 56,3 \\
\hline Alagoas & 24,7 & 19,0 & $-118,0$ & 38,1 & 156,1 & 132,3 \\
\hline Sergipe & 26,3 & 18,6 & $-47,0$ & 75,4 & $-122,4$ & 260,4 \\
\hline Bahia & 28,1 & 20,0 & $-1.161,9$ & $-76,7$ & $-1.085,2$ & 93,4 \\
\hline Nordeste & 23.6 & 19,1 & $-3.309,3$ & $-1.143,5$ & $-2.165,8$ & 65,4 \\
\hline
\end{tabular}

Fontes: Coluna I: Moura, Hélio \& Santos, Taís, Dinâmica demográfica recente dos estados e microrregiões do Nordeste, FUNDAJ-DESPO, Recife, 1986; Demais colunas: elaboração dos autores.

* A coluna representa o que seria o volume migratório do período 1980-91 se a população tivesse crescido vegetativamente no mesmo ritmo da década anterior.

As tabelas referidas apresentam as mesmas informações e resultados em nível de estados. No que concerne às taxas líquidas de migração, percebe-se grande variação, entre elas, no que se refere à grandeza, sentido e até sinais que as precedem. Vale notar que nos anos 70, apenas o Rio Grande do Norte situava-se na região como estado receptor de migrantes. Nos anos 80 manteve-se tal situação, o mesmo ocorrendo em Sergipe e Alagoas, que de estados emissores de população, converteram-se em estados receptores. 
Quanto aos demais estados, todos classificados na situação de emissores migratórios, a comparação entre as respectivas taxas líquidas atinentes aos dois últimos intervalos censitários, revela arrefecimento nos casos de Ceará, Piauí, Paraíba e Bahia, e intensificação, nos casos de Pernambuco e Maranhão. No caso do Maranhão, suspeita-se que a intensificação na emigração líquida esteja relacionada com a exaustão do antigo processo de absorção da população rural na sua fronteira ocidental, principalmente na sub-região do oeste maranhense, última área de fronteira agrícola disponível no Nordeste, a prática, pelas populações rurais do semi-árido afetadas pelas secas, da única estratégia não-urbana de sobrevivência de que dispunham. A tendência à exaustão dessa fronteira agrícola com o seu fechamento por fora e por dentro (18), houvera sido identificada por pesquisadores nordestinos há já algum tempo (19).

No que tange ao volume migratório dos estados, há que se considerar inicialmente o fato de o estado da Bahia, mercê da redução ocorrida na sua taxa de crescimento vegetativo - que praticamente reduziu em mais de $90 \%$ o seu potencial emigratório - haver se tornado um estado que, a persistir a tendência observada, poderá até se converter, em futuro muito breve, em estado receptor (líquido) de migrantes. A magnitude do volume emigratório (líquido) da Bahia no período entre 1980 e 1991 reduziu-se de tal modo que chegou a alcançar dimensão assemelhada à da Paraíba (apenas 77 mil emigrantes), ou seja, à dimensão de um estado cujo contingente populacional equivale a menos de uma terça parte do efetivo populacional baiano.

Os efeitos da queda da fecundidade foram mais sensíveis com relação às populações residentes naqueles estados que já se caracterizavam ou passaram a se caracterizar, nos anos 80, como receptores (líquidos) de migrantes: Sergipe, Rio Grande do Norte e Alagoas, aqui citados em ordem decrescente de importância. Entre os estados que se mantiveram como emissores (líquidos) de migrantes, o efeito inibitório da queda da fecundidade parece haver afetado em proporção maior os potenciais migratórios da Bahia, do Ceará e da Paraíba. Chama-se também a atenção para os casos do Piauí e de Pernambuco, cujos saldos emigratórios apresentaram crescimento entre os anos 70 e 80 a despeito da redução propiciada pela queda da fecundidade nos respectivos potenciais migratórios. É bem verdade ter sido o Piauí o estado nordestino onde a migração teria sido relativamente menos afetada pela queda da fecundidade cuja população potencialmente migrante teria sido a menos sensível à queda da fecundidade.

Contudo, no caso de Pernambuco, onde a queda da fecundidade ceifou mais de metade do respectivo potencial migratório, o crescimento do saldo emigratório líquido faz suspeitar de uma intensificação, durante os anos 80 , quanto à ação de fatores expulsivos de natureza sócio-econômica que, inclusive, estariam inibindo a orientação dos migrantes nordestinos de retorno em direção ao estado. $\mathrm{O}$ fraco crescimento populacional da região metropolitana do Recife nos últimos tempos seria um indício a mais a fundamentar essa suspeita. 


\section{A estrutura da população}

A estrutura etária e por sexo, ao mesmo tempo que reflete os efeitos de fatores que no passado foram atuantes ou intervenientes sobre a dinâmica de crescimento de uma população, também embute no seu seio elementos potenciais de consolidação ou de mudança na intensidade do crescimento potencial dessa população e em sua própria estrutura etária futura. Assim, o exame de como está evoluindo essa estrutura permite discernir ou antever em que faixas e quando poderão as pressões do crescimento populacional se tornar mais ou menos agudas, dando ensejo à formulação de propostas e/ou à aplicação de medidas tendentes a satisfazer as necessidades dessa forma gestadas ou a corrigir desequilíbrios sociais indesejáveis.

Na tabela 21 apresentam-se as distribuições absoluta e relativa por idade e as respectivas taxas de crescimento da população nordestina em 1980 e 1991 . As idades acham-se classificadas segundo algumas faixas consideradas mais relevantes para fins de análise sócio-demográfica e/ou de planejamento social: população infantil, população em idade escolar, população prestes a ingressar no mercado de trabalho, população em idades aptas para o exercício da atividade econômica, população idosa. Nessa mesma tabela constam informações semelhantes com relação ao país como um todo a fim de servirem de base a comparações (20).

Tabela 21

Brasil e Nordeste: população e taxas de crescimento segundo grandes faixas etárias - 1980-1991

\begin{tabular}{|c|c|c|c|c|c|}
\hline \multirow{2}{*}{ Discriminação } & \multicolumn{2}{|c|}{ Números absolutos } & \multicolumn{2}{|c|}{ Distribuição relativa } & \multirow[t]{2}{*}{$\begin{array}{c}\text { Taxa de } \\
\text { crescimento } \\
(\% \text { a.a. })\end{array}$} \\
\hline & 1980 & 1991 & 1980 & 1991 & \\
\hline \multicolumn{6}{|l|}{ Nordeste } \\
\hline 0 a 4 anos & 5,5 & 5,3 & 15,9 & 12,6 & $-0,4$ \\
\hline 5 a 9 anos & 4,9 & 5,8 & 14,2 & 13,6 & 1,4 \\
\hline 10 a 14 anos & 4,7 & 5,6 & 13,4 & 13,1 & 1,6 \\
\hline 15 a 59 anos & 17,4 & 21,8 & 50,0 & 51,4 & 2,1 \\
\hline 60 anos e mais & 2,2 & 3,1 & 6,3 & 7,3 & 3,2 \\
\hline Total & 34,8 & 42,5 & 100,0 & 100,0 & 1,8 \\
\hline \multicolumn{6}{|l|}{ Brasil } \\
\hline 0 a 4 anos & 16,7 & 16,6 & 13,8 & 11,3 & $-0,1$ \\
\hline 5 a 9 anos & 15,0 & 17,5 & 12.4 & 11,9 & 1,4 \\
\hline 10 a 14 anos & 14,5 & 17,0 & 12,0 & 11,6 & 1,5 \\
\hline 15 a 59 anos & 67,5 & 85,1 & 55,7 & 57,9 & 2,1 \\
\hline 60 anos e mais & 7,4 & 10,7 & 6,1 & 7,3 & 3,4 \\
\hline Total & 121,1 & 146,9 & 100,0 & 100,0 & 1,8 \\
\hline
\end{tabular}

Os efeitos da queda da fecundidade já se tornavam bem visíveis nos resultados censitários de 1991. Percebe-se redução no número absoluto de crianças 
nas primeiras idades e arrefecimento na tendência de crescimento dos demais grupos infanto-juvenis. Nesse sentido, há grande semelhança entre a evolução da população nordestina e da população brasileira na década passada. A participação relativa da população jovem em idades ainda inativas para o trabalho (menos de 15 anos) caiu significativamente no Nordeste e no Brasil entre 1980 e 1991, principalmente daquela classificada com menos de cinco anos de idade.

De modo geral, as mudanças na distribuição etária da população nordestina identificam o processo em curso de seu envelhecimento relativo: redução na participação relativa da população nas faixas etárias classificatórias de crianças (menos de 10 anos de idade), aumento na proporção de população em idades ativas ( 15 a 59 anos) e no segmento prestes a ingressar no mercado de trabalho (10 a 14 anos), aumento na proporção de pessoas com mais de 60 anos de idade (cujo contingente, apesar de ser bastante diminuto, foi o que mais rapidamente cresceu durante o período observado). São tendências que se mostram bastante assemelhadas à do paradigma brasileiro dos anos 80. O fato é que o grau de envelhecimento da população do Nordeste, embora ainda seja um dos mais baixos entre as regiões brasileiras (sendo a região Norte a exceção) evoluiu de 14,5 em 1980, para 18,6 em 1991 (21).

Note-se também que o crescimento da população em idades ativas (15 a 59 anos) já superou, durante os anos 80 , o ritmo de crescimento da população total, ocorrência que começou a se fazer notar em nível de Brasil (quadros urbanos) e de algumas de suas regiões desde a década dos 70, quando o declínio da fecundidade no Brasil começou a ganhar força. Em tal situação, tende a cair a taxa de crescimento da população total por efeito da redução absoluta e/ou relativa no número de nascimentos. Entretanto e contrariamente ao que quase sempre se imagina, a taxa de crescimento da população em idades ativas tende a permanecer no patamar anterior (ou a diminuir pouco e até mesmo a se elevar) durante muitos anos mais à frente, isto é, até que tenham passado pela faixa de idades ativas as várias coortes oriundas de períodos pretéritos de alta fecundidade. O declínio da mortalidade contribui também para a manutenção dessa taxa ao elevar a relação de sobrevivência das referidas coortes. A tabela 21 já revela, com relação ao período 1980/1991 a prevalência de uma taxa de crescimento geométrico anual do segmento de 15 a 59 anos da ordem de $2,1 \%$ ao ano, superior, portanto, à da população total $(1,8 \%$ ao ano) durante o mesmo período.

Assim, no momento atual e por muitos anos mais à frente, deverão pairar sobre os mercados de trabalho das regiões brasileiras - e o do Nordeste não constitui exceção - duas tendências do ponto de vista demográfico. De um lado, a tendência evolutiva da população em idades ativas, ou seja, da população que pressiona o mercado de trabalho. Tal tendência, no caso do Nordeste, mesmo sem levar em conta a desintensificação da migração líquida, deverá em futuro próximo, ser ainda de crescimento e não de debilitação. De outro, mesmo havendo alguma debilitação (supostamente indicada pela menor taxa de crescimento da população de 10 a 14 anos prestes a ingressar no mercado de trabalho), 
ainda assim o ritmo de crescimento do segmento em idades ativas deverá ser mais rápido do que o da população total. Significa dizer que a medida da necessidade de geração de empregos está deixando de ser dada pela taxa de crescimento da população total e passando a sê-lo pela taxa de crescimento específica do segmento populacional em idades ativas ( 15 a 59 anos).

Considerando também a pressão da mulher por maior incorporação à atividade econômica (inclusive para complementar a renda familiar), não parecem pairar dúvidas de que a taxa de crescimento da população potencialmente ativa poderá exceder bastante a que já foi referida. No Nordeste, esse período de intensa pressão sobre o mercado de trabalho deverá ir além daquele que habitualmente se estima corresponder ao do Brasil e suas regiões mais desenvolvidas (até 2005/2010) pelo fato de o declínio da fecundidade regional só ter ganho ímpeto mais tardiamente.

O exame das tendências alusivas aos vários segmentos da população permite não só traçar as perspectivas das demandas sociais que a eles estão associadas, como colocar nos devidos termos algumas das perplexidades com as quais já se defronta a sociedade ou que deverão continuar a afligi-la em dias vindouros.

Reconhece-se inicialmente a dificuldade que, em matéria de emprego, a sociedade nordestina deverá continuar experimentando, talvez até em escala ampliada. O crescimento da população em idades ativas, por sua intensidade e dimensão, suscita grande preocupação com respeito à possibilidade de serem gerados os empregos produtivos necessários ao atendimento da pressão exercida pela oferta de mão-de-obra. O quadro ganha nuanças ainda mais escuras devido, entre outros aspectos, à pouca capacidade de investimento que passou a ter o Estado brasileiro e ao aprofundamento das mudanças tecnológicas que estão, e deverão continuar, reduzindo a intensidade de utilização do fator trabalho por unidade de capital investido. Dias (1996) chama a atenção para o fato de que a humanidade - e os brasileiros não são exceção - está atravessando um momento crítico de sua história, pois começa a vivenciar o novo paradigma tecnológico, já em plena configuração. Vive-se, nesta virada de século, a passagem do paradigma eletromecânico para o microeletrônico, o que tende a apresentar implicações múltiplas sobre os sistemas produtivos, envolvendo de todas as formas a premência de rápida e ampla readaptação dos padrões educacionais e dos mercados de trabalho às novas necessidades que tal mudança encerra. $\mathrm{O}$ novo paradigma requer densidade bem menor do fator trabalho por unidade de capital e densidade bem maior que a atual do chamado capital intangível (educação de boa qualidade). Como admite Dias, sob o novo paradigma pode-se gerar um volume de desemprego que não guardará proporcionalidade nem com a população, nem com a disponibilidade de recursos naturais. $\mathrm{O}$ fato de o paradigma microeletrônico apresentar mais alta dinâmica tecnológica e, conseqüentemente, maior necessidade de constante aprendizado e adaptação, torna-o muito exigente quanto à necessidade de se poder contar com uma força de trabalho muito bem formada, desde os primeiros anos (22). 
Por outro lado, é paradoxal que a consideração atenta do que representam os ritmos de crescimento e os respectivos diferenciais nos quantitativos de população correspondentes aos segmentos populacionais em idades ativas e em idades idosas venha a deslocar o problema em curso da carência de recursos para financiar o sistema de previdência social de um âmbito eminentemente demográfico, como pretendem alguns, para alçadas outras, como parece mais apropriado. $\mathrm{Na}$ realidade, o problema básico consiste na inexistência de uma oferta abundante de empregos formais que possibilite gerar um fluxo de recursos financeiros para beneficiar uma população idosa crescente e mais longeva. A rigor, questão eminentemente demográfica seria se o crescimento da oferta de força de trabalho viesse a estar aquém, em futuro próximo, do crescimento do segmento idoso da população (como já ocorre em alguns países desenvolvidos). Ao contrário, o estágio atual da transição demográfica por que passa o Nordeste está propiciando e deverá continuar a fazê-lo, por bastante tempo ainda, condições exatamente opostas e teoricamente favoráveis à solução da questão, de um ponto de vista estritamente demográfico. O fulcro da questão, então, desloca-se para a necessidade de formulação e implantação de políticas de emprego abrangentes consistentes e coerentes que considerem tanto as dificuldades, quanto a dimensão dos problemas e suas múltiplas interrelações.

A tendência à queda na taxa de crescimento da grande massa populacional representada pelo segmento em idades infantis, rotulada de trégua demográfica por alguns analistas, têm sido por eles considerada, seja em nível de Brasil, seja em nível internacional (23). Para neomalthusianos mais ferrenhos, a diminuição da pressão alusiva às demandas sociais da população infanto-juvenil permitiria liberar recursos para a aplicação alternativa em investimentos econômicos diretamente produtivos. Já outros, menos radicais, chamam a atenção para o fato de que o arrefecimento na taxa de crescimento da população jovem daria ensejo à possibilidade de alternar novas necessidades infra-estruturais (construção de novos prédios escolares, postos pediátricos, centros de puericultura, entre outros) em favor da melhoria na qualidade já dimensionada do ensino, da saúde etc. Sem dúvida, partem do pressuposto equivocado de que, do ponto de vista quantitativo, essa população já estaria sendo suficientemente atendida. Contudo, são notórias as carências sociais que ainda persistem no Nordeste e afetam muito severamente substanciais contingentes da população infanto-juvenil. Parece, pois, ser ainda prematuro sequer sugerir realocação de recursos em benefício desta ou daquela faixa populacional, em benefício desta ou daquela forma de aplicação. Ampliação e extensão desses investimentos às amplas camadas infantis carentes parecem constituir proposta mais sensata.

\section{Sumário e considerações finais}

O estágio final da transição demográfica (queda de fecundidade) vem ocorrendo no Nordeste de forma até mesmo mais rápida do que se verificou em países hoje industrializados. Além disso, em tais países, ela se completou após ou à medida que iam sendo solucionados os graves problemas econômicos e sociais 
que lhes diziam respeito. Por outro lado, no momento histórico e nas circunstâncias em que neles ocorreu, havia importantes válvulas-de-escape, como a migração ultramarina, a lhes permitir, de certa forma, reduzir a dimensão de alguns dos seus problemas sociais. A automação industrial e o novo paradigma produtivo fundamentado na microeletrônica também não haviam ainda feito seu ingresso no sentido de estreitar e reduzir a capacidade de absorção da mão-de-obra pelo sistema produtivo.

No Nordeste, ao contrário, essa transição vem se dando em circunstâncias bastante diversas. A queda da fecundidade teve início antes mesmo que fossem atingidos níveis de mortalidade razoavelmente compatíveis com aqueles evidenciados pela experiência histórica. O fato é que as novas tendências da dinâmica demográfica regional deverão influir consideravelmente, a médio prazo, sobre o curso evolutivo e a distribuição espacial da população nordestina, além de imprimir mudanças no seu perfil etário. Haverá necessidade, certamente, de revisões, redimensionamentos e estabelecimento de novas prioridades de políticas sociais e econômicas, mesmo as que tiverem por horizonte um futuro não muito distante.

De um lado, nota-se que a população deverá continuar aumentando significativamente em números absolutos. Projeções de população realizadas em nível das microrregiões (24) permitem estabelecer como valores máximo e mínimo do efetivo populacional nordestino, por volta da virada do século, totais de 48,5 e 50,7 milhões de habitantes, com maior plausibilidade de o referido volume situar-se à volta de 49,5 milhões de residentes. No tocante à localização domiciliar, os efetivos urbano e rural do Nordeste deverão atingir, no ano 2000, magnitudes absolutas da ordem de 31,7 e 17,8 milhões de habitantes, respectivamente. O grau de urbanização regional tenderá a se elevar para 64\% a 65\%, mercê de taxa de crescimento da população urbana $(2,8 \%$ a.a. no período $1990 / 2000)$ que, embora cadente, deverá superar amplamente a do contingente rural (-0,2\% a.a.).

Contudo, a elevação do grau de urbanização não estará revelando, com toda a sua extensão, a dimensão do processo. Por efeito da migração, tenderão a crescer mais intensamente não apenas os efetivos dos quadros de residência urbanos daquelas microrregiões onde se localizam as principais cidades regionais (capitais estaduais e centros interiorizados tais como Imperatriz, Petrolina, Campina Grande, Mossoró etc.) mas também os efetivos rurais dessas mesmas áreas, refletindo o adensamento em torno desse núcleos. São populações já classificáveis com maior propriedade em termos de acesso a equipamentos urbanos, situação do emprego, relações de trabalho etc. como urbanas de fato.

Não obstante, é muito provável que o contingente rural do Nordeste, por estar decrescendo mais lentamente do que o do resto do Brasil, já passe, na virada do século, a ser majoritário com relação ao conjunto da população brasileira que persistirá residindo no campo. Assim, é possível admitir que a solução dos problemas sociais e econômicos que afligem os quadros rurais do país terá de contar com uma componente com forte matriz nordestino. 
No que diz respeito às mudanças no perfil etário da população nordestina, verificou-se já estar passando por processo relativamente rápido de envelhecimento relativo, tanto por efeitos sobre o topo da pirâmide etária quanto, principalmente, sobre a sua base. Ao longo do processo deverão se avolumar as dimensões de alguns dos graves problemas sociais com os quais já se defronta a região. Dentre eles deverá continuar avultando a questão do emprego, com todas as suas conseqüências. Os saturados mercados de trabalho nordestinos continuarão sofrendo a pressão da crescente oferta de mão-de-obra e porque essa pressão deverá se fazer sentir principalmente no meio urbano, é óbvio que as frustrações delas resultantes (acréscimo do desemprego e do subemprego, da desqualificação da força de trabalho, baixos níveis educacionais e culturais da população, entre outras) contribuirão para agravar toda a problemática social já existente, dando ensejo a perspectivas não muito otimistas quanto à tendência de agravamento da atual qualidade de vida nas cidades da região.

Crescente também deverá ser a demanda que pressionará os setores mais diretamente ligados ao atendimentos das necessidades da população idosa (medicina geriátrica, assistência social e previdenciária etc.) e que embutem a tendência de custos médicos crescentes. Por outro lado, a menos que se amplie significativamente o mercado de trabalho no sentido de absorver a massa crescente de novos contribuintes para a previdência social, poderá ocorrer a exaustão dos fundos disponíveis para fazer face não só ao volume relativamente maior de população idosa, mas também mais longeva.

No entanto, paradoxalmente, neste fim de século inicia-se um período no qual estarão sendo preenchidos, de ponto de vista estritamente demográfico, alguns importantes pré-requisitos favoráveis à solução de vários desses problemas. A desaceleração do crescimento do contingente jovem e a manutenção da taxa de crescimento do efetivo em idades ativas contribuirão para a rápida e sensível redução na razão de dependência da população regional, o que corresponderia, se todos estivessem trabalhando, à diminuição dos encargos sociais a serem suportados pelos participantes do mercado de trabalho. Por outro lado, o fato de que ainda durante algum tempo, a população ativa deverá crescer (tanto em termos absolutos, como relativos) de forma mais rápida do que a população idosa, constitui fator potencialmente favorável à geração de fluxos de recursos previdenciários destinados a suprir a demanda crescente a ela referente. Vê-se, portanto, que as soluções de muitos dos atuais problemas com que se defronta ou se defrontará a sociedade nordestina trazem no seu bojo a marca, as dimensões e os componentes precípuos de políticas de desenvolvimento econômico.

À guisa de conclusão, pode-se dizer que o novo século estará correspondendo a um momento em que a sociedade nordestina, sem haver resgatado a enorme dívida social contraída com grande parte de sua população, estará também se defrontando com custos sociais crescentes no sentido de satisfazer às necessidades ensejadas pelas novas estruturas demográficas que estão se configurando. Estruturas essas, frise-se, que não deverão se configurar de forma homogênea no vasto 
espaço regional, o que também exige, além de preocupação temporal, a formulação de políticas e a implementação de ações que se adeqüem às realidades de espaços sub-regionais específicos.

\section{Notas}

1 A expressão população titularmente urbana é aqui utilizada para referir o conjunto de pessoas residentes em cidades e vilas, independentemente de tamanho ou de outras qualificações que, a rigor, seriam necessárias para identificar e tipificar quadros de residência caracteristicamente urbanos.

2 A migração internacional, se bem que ainda relativamente diminuta, já não seria um fator totalmente a desprezar no tocante à determinação da taxa de crescimento populacional do país, a exemplo do que se verificava antes de 1980. Os anos 80 teriam presenciado o início da emigração líquida internacional de brasileiros à procura de emprego em outras partes do mundo: Canadá e Estados Unidos, alguns países europeus, Japão, alguns países sul-americanos etc.

3 Corresponde à proporção da população urbana que reside em quadros titularmente urbanos

4 Aqui conceituada como sendo a diminuição, em termos absolutos, da população residente em quadros rurais.

5 A propósito, vale relembrar que, ainda em meados dos anos 50, ao visitar Pernambuco, o padre J. Lebret, mentor da escola francesa Economie et humanisme, preocupado com a inchação da capital pernambucana, propunha às autoridades governamentais a estratégia de equipar certos núcleos da Zona da Mata com boa infra-estrutura e facilidades econômicas e sociais a fim de os mesmos funcionarem como anteparos aos grandes fluxos migratórios oriundos do Agreste e Sertão pernambucanos. Há um trabalho escrito por Lebret sobre a questão, editado pela antiga CONDEPE (Comissão de Desenvolvimento de Pernambuco).

6 Todaro, Michael P., A migração da mão-de-obra e o desemprego urbano em países subdesenvolvidos, In: Moura, Hélio A. de (org.), Migração interna: textos selecionados, Fortaleza, BNB/ENTENE, 1980, p.145-172.

7 Ver, a propósito, Moura, Hélio et al., Nordeste: migrações inter e intra-regionais, 1960/ 70, Recife, Sudene/BNB/ENTENE, 1975.

8 Moura, Hélio A. \& Santos Taís F., Projeção da população do Nordeste por microrregiões: 1980/2005, FUNDAJ (DESPO), Editora Massangana, 1990.

9 Moura, Hélio A., Nossas projeções de população por microrregiões: onde erramos? In: IX Encontro Nacional da ABEP, Anais. Caxambu, 1994, p. 432-449.

10 A taxa de fecundidade total é um indicador refinado que, ao contrário da taxa bruta de natalidade, não se deixa afetar por diferenciações na estrutura por sexo e idade da população. Corresponde, em média, ao número médio de filhos nascidos vivos por uma mulher durante o seu período reprodutivo (15 a 49 anos). 
11 Há já algum tempo, ao analisar o comportamento reprodutivo no Nordeste com base em dados que vinham até 1986, Taís Santos chamava a atenção para o fato de que a região Nordeste estaria brevemente apresentando níveis de fecundidade semelhantes aos das regiões mais desenvolvidas do país. Argutamente, fazia a observação de que, se por um lado a fecundidade nordestina convergia para o padrão das regiões econômica e socialmente mais desenvolvidas, por outro, não existiam evidências de que o padrão de vida da população caminhasse na mesma direção. Ver Santos, Taís F., Tendências recentes da fecundidade na região Nordeste e regiões metropolitanas de Fortaleza, Recife e Salvador. In VII Encontro Nacional da ABEP, Anais. Águas de São Pedro, 1990, p. 91-110.

12 A proporção de mulheres nordestinas com algum tipo de união conjugal e que já se achavam esterilizadas era, em 1996, de 43,9.

13 A esperança de vida ao nascer (ou vida média) corresponde ao número de anos que, em média, um recém-nascido de determinada coorte pode esperar viver, dada determinada lei de mortalidade.

14 Trata-se de um indicador o qual, por questões de natureza metodológica que não cabe tratar aqui, afigura-se mais confiável e vem sendo mais utilizado com relação a outros indicadores também resultantes da aplicação de técnicas indiretas de estimação. Ver, por exemplo, as edições mais recentes do estudo Situação mundial da infância da UNICEF.

15 Cf. Teixeira, Pery, Mortalidade da infância no Nordeste dos anos trinta aos noventa: um estudo de tendências. Recife, DESPO-FUNDAJ [inédito].

$16 I d . I b$.

$17 \mathrm{O}$ exercício baseia-se em técnicas indiretas de mensuração da mortalidade e da natalidade bastante sensíveis a erros e distorções e que podem afetar as informações básicas utilizadas. Os resultados apresentados, portanto, serão tanto mais confiáveis quanto mais forem considerados como indicadores de tendências e de diferenciais do que como mensuração precisa da magnitude absoluta dos fenômenos sob observação.

18 Cf. Osório, Carlos, Migrações recentes e desigualdades. I Encontro Nacional da ABEP, Anais. Campos do Jordão, 1978, p. 603-619.

19 Entre outros, Dornas, Helvécio, Dinâmica da ocupação do meio rural maranhense, Recife, Sudene, 1974; Jatobá, Jorge, Dinâmica demográfica e econômica na pré-Amazônia maranhense. I Encontro Nacional da ABEP, Anais. Campos do Jordão, 1978, p. 623-634; Targino, Ivan, Frente de expansão camponesa no Maranhão. Fortaleza, Revista Econômica do Nordeste, v.16, n.2, p. 183-210, abr./jun. 1985; Osório, Carlos, op. cit.

20 É importante ter o Brasil como base de comparação, pois constitui ele o modo mais inerente (por estar escoimado dos efeitos migratórios de curto prazo) à substância essencial que governa o processo do crescimento demográfico.

21 Esse grau corresponde à relação entre a população de 60 anos e mais e a população com menos de 15 anos de idade (vezes 100). Segundo o IPEA, esses índices, em 1991, 
teriam sido de 7,8 para a região Norte; 12,8 para o Nordeste; 16,5 para o Sudeste; 15,6 para o Sul; 9,3 para o Centro-Oeste; e 13,9 para o Brasil. Note-se, porém, que o cálculo do IPEA considerou, no numerador da expressão, a população de 65 anos e mais (e não a de 60 anos e mais, como consta deste texto). Ver, a propósito, o boletim Informações Demográficas, Brasília, IPEA/SEPLAN, nov. 1995.

22 Dias, Adriano Batista. População, emprego e desemprego tecnológico periférico: o avanço do paradigma microeletrônico. X Encontro Nacional da APEB, Anais. Caxambu, 1996, p. 569-582.

23 Expressão que não consegue disfarçar certo vezo neomalthusiano quando assim aplicada. De um ponto de vista estritamente neutro, também dever-se-ia considerar como trégua demográfica o período correspondente às condições ensejadas pela transição demográfica para que se possa operar, via criação de empregos, ao ajustamento entre a oferta e a demanda de recursos financeiros para atender às necessidades da previdência.

24 Moura, Hélio A. \& Santos, Taís, op. cit.

Hélio A. de Moura é pesquisador social e superintendente do Instituto de Estudos sobre a Amazônia da Fundação Joaquim Nabuco, Recife.

Pery Teixeira é pesquisador social e diretor do Departamento de Estudos Populacionais do Instituto de Pesquisas Sociais da Fundação Joaquim Nabuco, Recife. 